\title{
La pobreza humana y su feminización en España y las Comunidades Autónomas
}

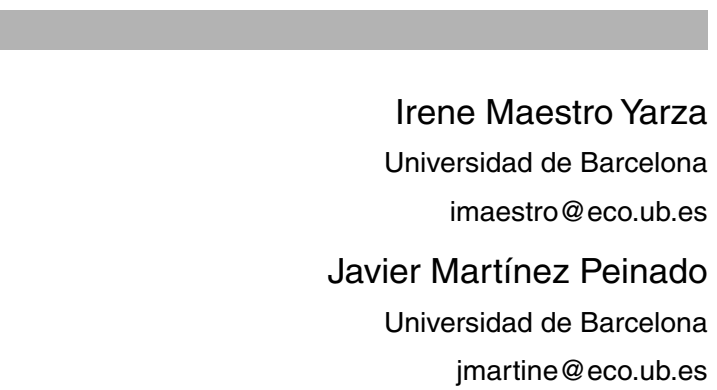

RESUMEN

El presente artículo ofrece una primera aproximación al fenómeno de la pobreza en España desde una perspectiva multidimensional, utilizando para ello la metodología propuesta por el Programa de las Naciones Unidas para el Desarrollo (PNUD) para este tipo de análisis, específicamente aplicada a los países industrializados. En España todavía no se ha realizado una investigación sistemática al respecto, ya que el enfoque generalizado en los estudios realizados hasta el momento ha sido el de ingreso. Por otra parte, y teniendo en cuenta que en las sociedades desarrolladas es fundamental considerar las diferencias territoriales y de género para caracterizar adecuadamente los niveles de desarrollo humano (en términos tanto de logros como de privaciones, como es el presente caso), el análisis de la pobreza humana se realiza para España y sus Comunidades Autónomas, por una parte, y se estima la feminización de dicha pobreza humana, por otra, es decir, se obtienen Índices de Pobreza Humana y de Pobreza Humana de Género.

Palabras clave: Pobreza, Pobreza Humana, Género, Comunidades Autónomas. 
Desde que en 1996 el Programa de la Naciones Unidas para el Desarrollo (PNUD) propuso el concepto de pobreza humana, integrado en su propuesta de nuevo paradigma de desarrollo humano, se ha ampliado sustancialmente la propia concepción teórico-metodológica y empírica de la pobreza, hasta entonces bastante restringida a una perspectiva de insuficiencia de ingreso monetario. Superando los debates clásicos al respecto mediante la construcción de índices multidimensionales y relativos (Índices de Pobreza Humana, IPH), el paradigma de la pobreza humana, en su concreción para los países desarrollados (IPH2), permite situar en sus verdaderas dimensiones los supuestos máximos logros en ellos obtenidos, al destacar los importantes sectores de la población privados de dichos avances. He ahí una de las fundamentales aportaciones del nuevo paradigma de la pobreza a la teoría y política sociales y del bienestar.

En España todavía no se ha realizado una investigación sistemática al respecto, ya que el enfoque generalizado en los estudios de pobreza ha sido el de ingreso. Urge introducir la perspectiva multidimensional propuesta por el PNUD, y en este artículo se ofrece una primera aproximación, derivada de una investigación más amplia ${ }^{1}$. Por otra parte, y teniendo en cuenta que, en las sociedades desarrolladas, es fundamental considerar las diferencias territoriales y de género para caracterizar adecuadamente los niveles de desarrollo humano (en términos tanto de logros como de privaciones, como es el presente caso), el análisis de la pobreza humana se realiza para España y sus Comunidades Autónomas, por una parte, y se estima la feminización de dicha pobreza humana, por otra, es decir, se obtienen Índices de Pobreza Humana y de Pobreza Humana de Género.

La temática se aborda en cuatro secciones. En la primera se aborda sintéticamente el tránsito del enfoque de la pobreza de ingreso al paradigma de la pobreza humana; la segunda sección se centra en el caso español, destacando el sesgo economicista de las aproximaciones hasta ahora existentes; en la tercera se explica la elaboración del IPH en España y las CC.AA., prestando especial atención a las dificultades empíricas para su construcción; por último, la cuarta sección trata de la feminización de la pobreza humana, con una propuesta novedosa respecto a su medición.

\footnotetext{
1 El presente artículo recoge parte de los resultados del trabajo de investigación «Desarrollo Humano y Pobreza: un enfoque de género", dirigido por Javier Martínez Peinado como investigador principal y financiado por el Instituto de la Mujer en el bienio 2000-2001 dentro del Programa Sectorial de las Mujeres y del Género, correspondiente al III Plan Nacional de Investigación Científica y Desarrollo Tecnológico. El equipo de investigación lo completan las investigadoras Gemma Cairó i Céspedes, Irene Maestro Yarza y Aurelia Mañé Estrada; y la becaria Marisa Sanz.
} 


\section{DE LA POBREZA DE INGRESO A LA POBREZA HUMANA: NIVEL TEÓRICO GENERAL}

Aunque se pueda decir que la pobreza, de una u otra manera, ha existido siempre, el origen y tratamiento de su acepción actual tienen sus raíces en el siglo XVIII, relacionada con el industrialismo y el proceso de asalarización a él asociado (Tortosa, 2001). Desde entonces, y vinculada a la desigualdad que el progreso capitalista no ha logrado atemperar, la situación de pobreza ha ido extendiéndose y adoptando nuevas formas conforme las estructuras socioeconómicas han ido evolucionando en el tiempo y en el espacio.

No existe una definición unívoca y universalmente aceptada del concepto de pobreza. Por el contrario, se han llegado a acuñar multitud de definiciones que son la consecuencia de un amplio espectro de interpretaciones y de enfoques posibles. En las tres últimas décadas, y con la agudización de los niveles de pobreza y de desigualdad en el mundo, se ha producido un intenso debate al respecto, que se ha llevado más al terreno de la medición que a consideraciones conceptuales de fondo, debido a la necesidad de definir objetivos y evaluar resultados concretos en las agendas y políticas de las diferentes conferencias y organismos internacionales.

El enfoque teórico de la pobreza del que se parte determina los indicadores que se van a utilizar para su medición, de tal manera que la complejidad alcanzada en la medición refleja la propia complejidad de la definición de la pobreza². Así, por una parte, puede hablarse de los enfoques subjetivo y objetivo de la pobreza y, por otra, del carácter absoluto o relati$v o$ de la misma ${ }^{3}$. El segundo enfoque ha sido el predominante, y el carácter relativo se ha ido imponiendo sólo paulatinamente, especialmente en Europa, sobre el absoluto, presente en los primeros estudios y todavía, en la actualidad, en Norteamérica y los países subdesarrollados ${ }^{4}$.

2 Para la relación entre teoría y medición, ver Martínez Peinado (1999).

3 Para un análisis más detallado de las distintas visiones conceptuales y variaciones sobre la pobreza, así como de las dificultades para su medición, ver Streeten (1998); Ruspini (1998); Harvey y Reed (1996); Veit-Wilson (1986), y Venanzi (1998). A pesar de las dificultades de aplicación del enfoque subjetivo, cabe destacar trabajos como los realizados por la Escuela de Leyden, a partir de sintetizaciones de la información subjetiva proporcionada por cada hogar en las diferentes Encuestas de Presupuestos Familiares (Hagenaars y Van Praag, 1985; Van Praag, Hagenaars y Van Weeren, 1982). En España, algunos trabajos del INE (1996) o de Martín-Guzmán y Bellido (1993) también utilizan este enfoque.

4 El ejemplo más reciente y conocido de uso del enfoque subjetivo lo constituye el informe del Banco Mundial sobre La voz de los pobres, dirigido por Narayan (2000), en lo que Toye (1998) califica de «evaluación participatoria de la pobreza». Respecto al debate sobre el carácter absoluto o relativo, éste incluye tanto la consideración de la problemática de las necesidades básicas (entre otros: VV.AA.,1980; Max-Neef, 1982; Doyal y Gough, 1994) como diferencias estructurales y temporales. Así, el trabajo de Rowntree (1901) sobre la sociedad británica de principios de siglo, a partir del modelo de pobreza absoluta, se ha señalado como pionero de este tipo de estudios, y en EE.UU. y Canadá se sigue fijando la línea oficial de pobreza valorando las necesidades mínimas de los individuos, mientras que en la Unión Europea se define explícitamente como pobres a 
La aparente disyuntiva a la hora de elegir entre una u otra alternativa es falsa, puesto que parece más conveniente trabajar simultáneamente con ambos criterios (Muñoz de Bustillo y Mora, 1998). Se puede argumentar que mientras que el enfoque absoluto es incapaz de reflejar aquellos componentes sociales (y por lo tanto «relativos») de la pobreza, el relativo tiene serias dificultades para recoger los aspectos de pobreza severa ${ }^{5}$, y que, como ya señalaba Sen (1985), existe un irreducible núcleo de pobreza, formado por todos aquellos elementos que dotan al individuo de capacidad para funcionar (nutrición, participación en la sociedad y transporte) (nivel absoluto), mientras que donde cabe observar diferencias sociales es en la forma de obtención de esas capacidades (nivel relativo).

Convencionalmente, y bajo la influencia de un enfoque utilitarista del concepto del bienestar, hasta hace pocos años se ha tendido a definir a la pobreza como un nivel de vida material inaceptablemente bajo (de donde se ha inferido que el nivel de vida material de una persona determina su bienestar), bien sea en comparación con el nivel de vida de otros en una sociedad (pobreza relativa), bien en relación con algún mínimo absoluto (pobreza absoluta). En general, ese nivel de vida se ha tendido a medir a través de dos variables alternativas, pero siempre económicas: el gasto o el ingreso corriente, seleccionando un umbral o límite por debajo del cual se considera que la gente es pobre ${ }^{6}$. Ese límite, como señala el PNUD (1996), es determinado arbitrariamente, habiendo siempre diferentes opiniones acerca de cuánto dinero es necesario para escapar de la pobreza (brecha de pobreza), que derivan, en cualquier caso, en políticas nacionales o internacionales de marcado carácter asistencialista.

En los años noventa, sin embargo, tanto el Banco Mundial ${ }^{7}$ como — sobre todo- el PNUD abordan el análisis de la pobreza desde una perspectiva más amplia y multidimensional,

"aquellas personas, familias o grupos cuyos recursos - materiales, culturales y sociales - son tan limitados que les excluyen del modo de vida mínimo aceptable en el estado miembro en el que habitan» —Eurostat (1992), en una clara visión relativaPor su parte, en los países subdesarrollados se mantiene el carácter absoluto, probablemente por la elevada proporción de población que en estos países no tiene cubiertas unas necesidades que se podrían considerar básicas, en una situación que se podría calificar de pobreza extrema.

\footnotetext{
5 Vale la pena señalar en este punto que el debate pobreza absoluta/relativa obedece a otros aspectos que trascienden al marco conceptual de la pobreza, para entrar en el terreno de las consideraciones ideológicas y/o políticas. Así, aquellos defensores del criterio absoluto se han situado en posiciones desde las que se exige una menor intervención por parte del sector público para su solución, puesto que bastaría con un Estado del Bienestar residual que se limitara a ayudar a aquellos incapaces por sí mismos para alcanzar ese mínimo claramente definido (en términos estrictamente biológicos en su versión más estrecha). Mientras que, por su parte, el criterio relativo, al ampliar el campo de definición de la pobreza (asociándolo incluso con la desigualdad en la distribución de la renta y/o de la riqueza), tiene implicaciones políticas evidentes y exigiría un nivel de intervención pública mucho mayor.
}

6 Como se discutirá más adelante, el umbral más frecuentemente utilizado es el del $50 \%$, bien de la media o bien de la mediana, del ingreso equivalente; y se reduce al $25 \%$ para hablar de pobreza extrema.

7 En 1990, el Banco Mundial dedicó su Informe sobre el desarrollo mundial precisamente a este tema, y empezó a incorporar otras dimensiones - además de la del ingreso- en el análisis de situaciones de pobreza. Diez años después, la misma insti- 
superando esa tradicional visión reduccionista del ingreso, y ofreciendo, en el caso del PNUD, un método alternativo de medición ${ }^{8}$. Si bien el PNUD no ha sido el único que ha realizado avances en este sentido, su gran aportación ha sido, como señala Tortosa (2001), permitir un trabajo comparativo (tanto transversal como longitudinal) prácticamente imposible en otras experiencias ${ }^{9}$. En la segunda mitad de la década, de acuerdo con el nuevo paradigma del desarrollo humano, el PNUD aborda así el fenómeno de la pobreza desde una perspectiva más amplia, sosteniendo que la «pobreza de ingreso» es sólo una parte de sus componentes y, de la misma manera en que se postula que el desarrollo humano abarca aspectos de la vida mucho más amplios que el ingreso, debe considerarse que la pobreza tiene, asimismo, varias dimensiones, y puede abordarse desde diferentes perspectivas (ingreso, necesidades básicas...). De entre ellas, el PNUD destaca la de la capacidad (adoptando así las propuestas de A. Sen). A diferencia del ingreso, la capacidad es un fin, reflejado no en el insumo sino en el producto humano, es decir, en la calidad de vida de la gente. La privación se refleja en la falta de capacidad básica cuando la gente no tiene posibilidad de llegar a ciertos niveles esenciales de logros humanos o de funcionamientos, que son, según Sen, «constitutivos» del estado de una persona y cuya estimación tiene que formar parte de cualquier evaluación del bienestar de esa persona (Sen, 1995).

Todo ello supone adoptar una concepción relativa, dinámica (como un proceso más que como un resultado) y multidimensional de la pobreza ${ }^{10}$. Se asume así el análisis de la pobreza desde el paradigma de las capacidades y oportunidades que caracterizan al desa-

tución propone un cambio de paradigma al respecto, reforzando la multidimensionalidad, a la vez que proclama que su objetivo es la lucha contra la pobreza en el mundo. En definitiva, pone a esta temática como protagonista de las políticas internacionales de cooperación y desarrollo.

\footnotetext{
8 A pesar de que el concepto de desarrollo humano nació muy ligado a la idea de «privación» —el propio Índice de Desarrollo Humano (IDH) se calculaba en los primeros años de su elaboración a partir del nivel de privación de las personas en tres ámbitos básicos-, el concepto de pobreza desde la perspectiva del desarrollo humano no fue explicitado por el PNUD hasta el Informe de Desarrollo Humano de 1996, en el cual se introdujo el Índice de Pobreza de Capacidad (IPC), como complemento de los índices de pobreza de ingreso, para sustituirlo por el definitivo Índice de Pobreza Humana (IPH) al año siguiente.

9 Ejemplos de otras iniciativas de medición multidimensional de la pobreza, anteriores a las del PNUD, se pueden encontrar en Milano (1992), quien utiliza un índice, aplicado a Noruega, que incorporaba elementos de salud, inserción social, situación de trabajo, condiciones de alojamiento e ingresos; o también Townsend (1993), quien considera pobres a los individuos, familias o grupos que carezcan de los recursos para obtener el tipo de dieta, participar en las actividades y tener las condiciones de vida habituales, o ampliamente aceptadas, en las sociedades a las que pertenezcan; o también VV.AA. (1995). Para España son destacables los trabajos de Zarzosa (1992) y Zarzosa et al. (1996), donde se plantea una discusión multidimensional del bienestar social; y más recientemente otros autores como Martínez y Ruiz-Huerta (1999) están abriendo líneas de investigación que intentan medir específicamente el fenómeno de la pobreza en España con variables multidimensionales.

10 El carácter relativo del concepto de pobreza humana quedó rubricado en 1998 cuando el PNUD propuso unas variables de medición y unos umbrales específicos para estimar la pobreza humana en los países industrializados (IPH-2) diferentes a los utilizados desde 1997 para los países subdesarrollados (IPH-1). Hecho que, como se puede comprobar en Chossudovsky (1998), no ha estado exento de polémica.
} 
rrollo humano, conectando ambos ámbitos de la existencia de las personas, desarrollo y pobreza, logros y privaciones, como el positivo y el negativo de una película.

\section{Las dificultades empíricas de medición de las capacidades acaban resolviéndose a través} de la medición de la privación en oportunidades en las esferas consideradas fundamentales (vida larga y saludable, educación y nivel de vida), aunque el propio PNUD reconoce que la pobreza es más amplia que cualquier medida que se pueda estimar de ella (incluido el IPH) ${ }^{11}$. En su Informe de 1996 propuso el Índice de Pobreza de Capacidad (IPC), con el objetivo de complementar los diferentes indicadores de pobreza de ingreso ${ }^{12}$. Un año después, en 1997, optó por el Índice de Pobreza Humana (IPH), que presentó como continuador del IPC, aunque resulta ser más “convencional» ${ }^{13}$. Por otro lado, e introduciendo un criterio de pobreza relativa, se argumentó la inviabilidad de un único índice de pobreza humana de validez universal, ya que las privaciones en los países subdesarrollados (hambre, analfabetismo, epidemias, falta de servicios de salud o de agua potable, etc.) son poco relevantes en los países desarrollados, en los que la pobreza se manifiesta de otras formas. Por tal motivo se elaboraron dos indicadores de pobreza humana, uno, el IPH-1, definido específicamente para los países subdesarrollados, y el IPH-2, referido a los países industrializados. Ambos indicadores miden la privación de las tres dimensiones esenciales de la vida humana reflejadas en el IDH: la supervivencia, el nivel de conocimientos y el nivel de vida, vinculado a un nivel digno de aprovisionamiento económico general. La variación entre el IPH-1 y el IPH-2 estriba en las variables y umbrales utilizados para calcular sus componentes ${ }^{14}$.

\footnotetext{
11 Así, la falta de libertad política, la incapacidad para participar en la adopción de decisiones, la falta de seguridad personal, la incapacidad para participar en la vida de una comunidad, y las amenazas a la sostenibilidad y la equidad intergeneracional, son todas ellas dimensiones fundamentales de la pobreza humana, pero que quedan excluidas del IPH.

12 EI IPC era un índice simple, calculado como la media aritmética de tres indicadores que reflejaban el porcentaje de la población con deficiencias en su capacidad en tres aspectos básicos del desarrollo humano: el de estar bien alimentado y sano (reflejada por la proporción de niños menores de cinco años con peso insuficiente); el de la procreación en condiciones saludables (reflejada por la proporción de nacimientos sin asistencia de personal de salud capacitado); y el de tener educación y conocimientos (representada por la tasa de analfabetismo adulto —-mayores de quince años— femenino). Especial mención merece este último indicador, que suponía convertir una medida de género en una medida global de desarrollo, por el convencimiento de que la privación de la mujer afectaba negativamente al desarrollo humano de las familias y de la sociedad en general, siendo además uno de los sectores más críticos de la sociedad. Por otra parte, puede observarse que, a diferencia del $\mathrm{IDH}$, no incorporaba ningún indicador de ingreso.
}

${ }^{13}$ El IPH se concentra en un conjunto más amplio de variables que lo relacionan de forma coherente con el IDH, aunque también implica el abandono de cualquier indicador que haga referencia explícita a la mujer. El resultado es, como señala Dubois en Pérez de Armiño (2000: 434), un indicador más convencional que el IPC, cuyos resultados son menos negativos no sólo que los del IPC, sino incluso que los arrojados por algunos otros indicadores de pobreza de ingreso (1 dólar diario, establecido por el Banco Mundial).

14 En el IPH-1 las carencias en longevidad se miden a través del porcentaje de personas que se estima que no sobrevivirán a los cuarenta años; la privación en términos de conocimientos a través de la tasa de analfabetismo adulto; mientras que la tercera de las privaciones se mide por la media aritmética de tres variables, dos de las cuales incorporan el aprovisionamiento 
En la construcción del IPH-2, que es el que corresponde al presente trabajo, se parte de cuatro tasas porcentuales, a las que el PNUD denomina índices, para asimilarlos terminológicamente a los componentes del IDH:

- El porcentaje de personas que se estima que no sobrevivirán más allá de la edad de 60 años, que aquí se denominará Índice de Privación de Salud (IPS).

- El porcentaje de adultos que son funcionalmente analfabetos ${ }^{15}$, que aquí se denominará Índice de Analfabetismo Funcional (IAF).

- El porcentaje de personas que viven por debajo del umbral de la pobreza (cuyo ingreso personal disponible es inferior al 50\% de la mediana del ingreso), que será el índice de Pobreza de Ingreso (IPI).

- La tasa de desempleo de larga duración, que se calificará como el Índice de Exclusión Social (IES).

EI IPH-2 se construye como la media cúbica de los porcentajes que expresan las privaciones de las personas pobres, según la fórmula

$$
\mathrm{IPH}-2=\left[1 / 4\left(\mathrm{IPS}^{3}+\mathrm{IAF}^{3}+\mathrm{IP} \mathrm{I}^{3}+\mathrm{IES} \mathrm{S}^{3}\right)\right]^{1 / 3}
$$

y expresa el porcentaje, sobre la población total, de personas en condiciones de pobreza humana.

Este será el índice que se presenta, en este trabajo, para España y las Comunidades Autónomas, y tanto para hombres como para mujeres.

\section{LOS ESTUDIOS DE POBREZA EN ESPAÑA: EL REDUCCIONISMO AL INGRESO}

Los estudios de la pobreza en España son relativamente recientes y, de hecho, fueron muy escasos hasta la década de los ochenta ${ }^{16}$. Sólo a partir de mediados de dicha década (y

económico de ingreso público (porcentaje de personas sin acceso a agua potable y porcentaje de personas sin acceso a servicios de salud), mientras que la tercera tiene que ver con el aprovisionamiento privado (porcentaje de niños menores de cinco años de edad con un peso moderadamente y severamente insuficientes).

15 El concepto de analfabetismo funcional está basado en la definición de la OCDE (1997), según la cual son analfabetos funcionales aquellas personas que carecen de la capacidad para leer y escribir adecuada a las exigencias más fundamentales de la sociedad moderna, es decir, que carecen de la capacidad para comprender y usar información impresa en las actividades cotidianas del hogar, el trabajo y la comunidad.

16 Para un recorrido cronológico y detallado de estos estudios, ver Cantó, Del Río y Gradín (2000); y Ayala y Renes (1998). 
sobre todo en los años noventa) se empezaron a generalizar este tipo de estudios que, mayoritariamente, han partido de una concepción de pobreza basada fundamentalmente en la dimensión del ingreso, incluyendo, a lo sumo, esbozos del perfil socioeconómico de aquellos grupos que, previamente, han sido identificados como pobres a partir de un determinado umbral de ingreso (o de gasto). Tales estudios se enfrentaban a la falta de información estadística adecuada y a cierta imprecisión conceptual, y a partir de mediados de los ochenta experimentaron un giro hacia el enfoque relativo de la pobreza, tras una primera etapa de predominio exclusivo del enfoque absoluto.

El informe de EDIS-Cáritas (1984) estableció como umbral de pobreza el 50\% de la renta media mensual —que en 1983 era de 12.500 pesetas al mes-. A partir de entonces, parece existir cierto consenso en todos los estudios realizados en España respecto a adoptar dicho porcentaje (tanto de la renta como del gasto), calificando como pobreza moderada la situación entre el 25 y el 50\%, y como pobreza severa la situación por debajo del $25 \%$ (complementando el análisis, en ocasiones, con información respecto a otros porcentajes -40 ó $60 \%$ como opciones más frecuentes-). Otras opciones adicionales son la elección del estadístico, la media o la mediana ${ }^{17}$, y de la variable, la renta o el gasto.

En España, la mayor parte de los trabajos han optado por la media (una excepción es Cantó, 1997). Existen, sin embargo, varios procedimientos para calcular dicha media, y los resultados difieren según el método utilizado. El procedimiento más habitual ha sido ponderar los ingresos o gastos de cada hogar encuestado según el número de miembros y según el factor de elevación asignado a cada observación de la muestra para obtener totales poblacionales ${ }^{18}$. Y respecto a la variable de referencia, la mayoría de estudios se ha decantado por el gasto, ya que la principal (y más utilizada) fuente estadística, la Encuesta de Presupuestos Familiares (EPF), le confiere más fiabilidad que al ingreso, aunque los estudios que utilizan fuentes (encuestas) propias, como los de Cáritas, normalmente utilizan el ingreso como variable de referencia.

Existen experiencias de fijación consensuada socialmente de los umbrales de pobreza, pero no es el caso español, en el que, como mucho, se ha evaluado la percepción subjetiva de los pobres de su propia situación. Con la incorporación al cuestionario de la EPF de 1990-91 de un módulo de preguntas subjetivas se abre una posibilidad de profundización

\footnotetext{
17 Quienes optan por el uso de la mediana lo justifican por el hecho de que se trata de una medida menos sensible a las rentas extremas que la media, además de presentar una mayor estabilidad temporal que esta última, por lo que la mediana se suele utilizar sobre todo en estudios dinámicos.

18 El factor de elevación se aplica para corregir la ocultación por parte de los encuestados de los ingresos obtenidos. Este factor es estimado por el propio encuestador o bien a partir del cruce de información con otras fuentes indirectas tales como la Contabilidad Nacional.
} 
de esta vía de análisis ${ }^{19}$. Pero, frente a la experiencia de otros países en los que existe una «renta mínima» o «básica» (utilizable como «umbral legal» de pobreza) a escala estatal, en España las «rentas mínimas» son diferentes según cada Comunidad Autónoma, y además no están siempre definidas específica y explícitamente como umbrales de pobreza. A nivel estatal, pues, no hay un pivote ampliamente aceptado sobre el que definir la situación de pobreza (de ingreso).

Respecto a la unidad de análisis, en España, hasta la aparición del estudio de EDIS-Cáritas (1984), se utilizó el hogar, independientemente del número de integrantes del mismo. Posteriormente se optó por estimar la pobreza a partir de la renta o del gasto per cápita, lo que no dejaba de ser inexacto, dado que no se tenían en cuenta las posibles economías de escala dentro de cada hogar. Ya en los noventa se adoptó, de manera generalizada, la escala de la OCDE ${ }^{20}$, aunque con anterioridad algunos trabajos habían introducido algunas novedades al respecto ${ }^{21}$. El fuerte componente discrecional a la hora de decidir los pesos relativos de cada miembro del hogar, la no diferenciación entre las necesidades de los menores con edades muy diferentes, y el sobredimensionamiento con el que se siguen considerando las necesidades de los hogares más grandes, son las principales críticas a esta aproximación.

\section{Los primeros intentos cuantitativos serios de los años sesenta del ICE ${ }^{22}$, del Plan CCB de Cáritas $^{23}$ o del Informe FOESSA ${ }^{24}$ presentan demasiadas diferencias metodológicas y con-}

\footnotetext{
19 Se pueden señalar los trabajos de Martín-Guzmán y Bellido (1993), quienes realizaron las primeras estimaciones de estas líneas de pobreza en España; o los de Ruiz-Huerta y Martínez (1994), donde la percepción subjetiva se combina con los ingresos disponibles y el equipamiento del hogar.

20 Dicha escala atribuye a los adultos distintos del sustentador principal una ponderación equivalente al $70 \%$ del cabeza de familia y un $50 \%$ para cada uno de los menores de edad.

21 Escribano (1990) utilizó escalas de equivalencia de Engel, intentando incorporar las evidentes economías de escala que se obtienen de la convivencia de varios individuos en un mismo hogar. Otra aportación interesante en este sentido, aunque posterior en el tiempo, es la de Duclos y Mercader-Prats (1999), quienes llevan a cabo un completo análisis de sensibilidad de los resultados de pobreza según la escala elegida. Según estos autores, para el caso de España y para 1980-81, puede darse hasta un $10 \%$ de variabilidad en el número de pobres dependiendo de la escala utilizada. También en este sentido, el INE (1996) realizó un detallado análisis de sensibilidad de sus resultados de pobreza utilizando las tres EPFs disponibles. Posteriormente, Del Río y Ruiz-Castillo (1997c, 1999) llevan a cabo un análisis general de los efectos del uso de diferentes índices de pobreza, escalas de equivalencia y líneas de pobreza, utilizando para ello curvas TIP. Los resultados concluyen que, cualquiera que sea la opción tomada, entre 1973, 1980 y 1990, la pobreza disminuye en España.
}

22 El trabajo del ICE (1962), además de su carácter pionero, es destacable por presentar un enfoque de características muy avanzadas para el momento, como es, por un lado, la utilización de datos obtenidos de la Encuesta de Cuentas Familiares (predecesora de la Encuesta de Presupuestas Familiares-EPF), elaborada por el INE; y, por el otro, la utilización de algo que será muy habitual años después, las escalas de equivalencia similares a la escala OCDE en la definición del gasto del hogar.

23 Plan de Comunicación Cristiana de Bienes (CCB), puesto en marcha por Cáritas en 1965.

24 El Informe FOESSA (1966) tenía como objetivo la cuantificación e identificación de los hogares pobres absolutos en España, partiendo para ello de la utilización de encuestas directas a las familias españolas. El escaso nivel de respuesta a dichas encuestas limitó enormemente las posibilidades de éxito de este estudio. 
ceptuales como para poder ofrecer una visión conjunta coherente (Cantó, Del Río y Gradín, 2000), y en la década siguiente no se avanzó mucho más ${ }^{25}$. En conjunto, de los escasos estudios realizados y difundidos cabe concluir que España presentaba entonces unas características típicas de país de reciente industrialización y rápida urbanización, y donde si, por una parte, se había conseguido la cobertura de algunas necesidades básicas como la alimentación, se agudizaban las carencias de tipo infraestructural (vivienda y equipamiento básico, fundamentalmente). En suma: el rápido crecimiento económico del «milagro español» implicó una reducción de la pobreza severa pero un aumento en la desigualdad de la renta (Alcaide, 1993). La crisis económica de los setenta, que disparó el desempleo, tendría que haber provocado también un aumento de la pobreza, aunque la consolidación de algunas instituciones y prestaciones básicas podrían haber contrarrestado este efecto, pero la ausencia de estudios en la época impide conclusiones sólidas al respecto. Habrá que esperar al final de los ochenta para contar con trabajos que iluminen la situación de la década anterior: Bosch, Escribano y Sánchez (1989) y Martín-Guzmán y otros (1996)26 coinciden en mostrar una ligera tendencia a la reducción de la pobreza entre el inicio de la crisis y el final de la década. Por su parte, las estimaciones de FOESSA-Cáritas (Ayala y Renes, 1998) vienen a confirmar, con otra metodología empírica, tales extremos.

En la década de los ochenta, la publicación del informe «Pobreza y Marginación» de EDIS-Cáritas (1984) —con la famosa cifra de los 8 millones de pobres ${ }^{27}$, que sacudió a la opinión pública- sirvió de revulsivo para la realización de otros estudios al respecto. En el mencionado informe se aportaba, por primera vez, un cuadro global de la extensión de la pobreza en España (intensidad, distribución, e incluso las actitudes sociales de la población frente a ese fenómeno) y se esbozaba la estrecha conexión entre desigualdad y pobreza. Simultáneamente, otra investigación del Ministerio de Trabajo, titulada «Pobreza e Inseguridad en España», que no llegó a ser publicada, concluía, según se menciona en el informe de EDIS-Cáritas (1998), unas tasas de pobreza aún mayores. A partir de una concepción de la pobreza muy restrictiva, según la cual el umbral de pobreza se fijaba en el $50 \%$ de la renta media mensual, más del $20 \%$ de la población española se podía considerar pobre.

El creciente interés académico e institucional sobre el tema auspició la ampliación de fuentes de datos (p. ej., microdatos de la EPF) y estudios (Ruiz-Castillo, 1987; Bosch y

\footnotetext{
25 Durante los años setenta, los estudios se centran en el análisis de la desigualdad en la distribución de la renta, partiendo para ello de la explotación de la información contenida en la EPF.

26 Todos ellos pretenden comparar la situación de pobreza y desigualdad entre 1973 y 1980 (y hasta 1990 en el caso de Martín-Guzmán), utilizando el gasto por habitante como variable de referencia.

27 Desglosado en una tasa de pobreza del $18 \%$ en zonas urbanas, frente a casi un $25 \%$ en las rurales.
} 
otros, $\left.1989^{28}\right)$, que se multiplican, en particular, con la explotación de los datos de la EPF de 1990-9129, incorporando, además, el enfoque relativo, frente al absoluto de los trabajos anteriores. Estos estudios se enfrentaron, además, a la compleja dinámica económica, política y social de la década de los ochenta - crisis y posterior recuperación, consecuencias de la entrada en la UE en el (des)empleo pero también en fondos sociales, aumento del gasto social en términos absolutos y relativos, etc.- - Además, ya en los ochenta empezaron a aparecer los primeros estudios por CC.AA., multiplicándose en los noventa ${ }^{30}$. En dicha década, por otra parte, y como ya se ha citado, se dispondrá de dos nuevas fuentes de datos sobre ingresos y gastos de los hogares: la EPF de 1990-91 y las sucesivas actualizaciones de las Encuestas Continuas de Presupuestos Familiares (ECPF), realizadas cada tres meses, que, si bien con carencias en términos de representatividad, resultan indicativas de la evolución de la pobreza (Cantó, Del Río y Gradín, 2000). También el proceso de integración europea tuvo su contrapartida en los temas de pobreza, ya que algunos indicadores de pobreza españoles fueron incluidos por primera vez en marcos de

28 Ruiz-Castillo lleva a cabo, de manera original y completa, los primeros cálculos de los diferentes índices propuestos en la literatura anglosajona, como por ejemplo los señalados por Sen (1983) o Atkinson (1987b). Según este trabajo, los hogares pobres entre $1980-81$ representaban el $14,4 \%$ del total de hogares, mientras que los individuos representaban el $17 \%$ de la población española total. Por su parte, Bosch y otros aportan el estudio de la evolución de los índices de pobreza desde principios de la década de los setenta hasta los inicios de los ochenta, utilizando el $50 \%$ del gasto per cápita como línea de pobreza. Según estos autores, en 1973 el porcentaje de individuos pobres representaba el 17,9\% de la población total, para reducirse al 16,8\% en 1980. Posteriormente, Escribano (1990) amplió este estudio hasta mediados de los ochenta, hasta 1987 para ser exactos. Los resultados, en términos de hogares pobres, fueron: para 1973, del 18,9\%; para 1980, del 17,9\%; para 1985, del 18,3\%; y para 1987, del 16\%. La variable utilizada también fue el $50 \%$ del gasto medio per cápita, aunque aplicando algún tipo de ajuste a la composición de los miembros de las diferentes familias.

29 A este respecto, ver, entre otros: EUROSTAT (1992), que en 1987 situaba la proporción de pobres en el 16,9\% de la población y en el 17,5\% de los hogares; Duclos y Mercader-Prats (1993), revisado en (1999); y Mercader-Prats (1993, 1995, 1998), todos ellos estudios comparativos de la pobreza en España, Francia y el Reino Unido, a partir de diferentes elecciones metodológicas de cálculo; Ruiz-Huerta y Martínez (1994), donde se sitúa la proporción de individuos pobres (por debajo del 50\% del gasto equivalente) en un $19,6 \%$ en 1980 , para descender a un 17,9\% en 1990; mientras que tales proporciones varían si se utiliza la variable del $50 \%$ del ingreso equivalente, así en 1980 había un 18,4\% de individuos pobres, mientras que en 1990 la proporción fue del 15\%; INE (1996), en cuyo trabajo se utilizaron tanto la variable del gasto como la de ingreso, así como algunos datos multidimensionales de la pobreza; según la variable del gasto, los hogares pobres pasaron de representar el $22 \%$ en 1973, al 20,6\% en 1980 y al 19\% en 1990; según el ingreso, en esos mismos años, los porcentajes de hogares pobres fueron sensiblemente inferiores: $21,4,19,9$ y $16,5 \%$, respectivamente; y Ayala (1998).

30 Un primer acercamiento al tema lo realizó Ruiz-Castillo (1987). También es destacable la labor realizada por el equipo de Economía Cuantitativa del Bienestar de la Universidad de Málaga, quien, a partir de la EPF, incorporó una perspectiva territorial de la pobreza mucho más desagregada que las anteriores, incorporando además un novedoso cuerpo teórico y empírico sobre sus posibles factores explicativos. Algunos ejemplos al respecto son: García Lizana y otros (1989) y Martín Reyes y otros (1989). Ya en la década de los noventa, cabe señalar los trabajos realizados por Comunidades Autónomas de Ruiz-Huerta y Martínez (1994), INE (1996) y FOESSA (1998). Además, algunos trabajos genéricos sobre España también incorporan un análisis regional; de entre ellos, el de Del Río y Ruiz-Castillo (1997c; 1999a) presenta la novedad de utilizar tanto líneas de pobreza regionales como nacionales, de manera que se pueda diferenciar la situación de la cola baja de la distribución en su entorno más cercano y también analizar su convergencia con el contexto nacional. Por lo que respecta a los estudios específicos sobre la pobreza en determinadas Comunidades Autónomas, éstos han proliferado en los últimos años. Así, Oliver (dir.) (2001), Mercader y Delicado (1998), Sierra y Corral (1998) y Gradín y Del Río (2000) se han centrado en las CC.AA. de Cataluña (los dos primeros), País Vasco y Galicia, respectivamente. También merecen especial mención los trabajos publicados en la Revista de Estudios Regionales, que estudian la pobreza en CC.AA. como Andalucía, Aragón y otras. 
análisis comparados suficientemente homogéneos ${ }^{31}$. Sin embargo, todavía son pocos los estudios de este tipo.

Concluyendo, y como señalan Ayala y Renes (1998), todavía persisten muchas lagunas, tanto por lo que respecta al conocimiento integral de la pobreza como por lo que se refiere a las actuaciones concretas para atajarla (muy circunscritas al ámbito local o regional). De hecho, aún no resulta fácil saber qué pasó a lo largo de los noventa, dado que no se dispone de la suficiente información sobre la multitud de factores al respecto: la dinámica estructural y cíclica del (des)empleo, la adaptación de los gastos sociales y de los procesos de desregulación y liberalización de un amplio número de actividades a los criterios del Tratado de Maastricht, los cambios en los sistemas de tributación, etc., factores todos ellos que contribuyeron a aumentar las desigualdades salariales. En base a su consideración, y a partir de las únicas evidencias empíricas de las que se dispone (el PHOGUE y las estimaciones realizadas por la ECPF), parece poder concluirse que, cualquiera que sea la opción metodológica adoptada, la pobreza ha aumentado respecto a las cifras de 1990. Pero, también intuitivamente, se puede suponer que la consolidación de una cierta red de seguridad económica, como consecuencia de la ampliación de las prestaciones asistenciales, puede haber contribuido a reducir la pobreza severa.

En tiempos recientes se han abierto nuevas líneas de trabajo - $y$ se ha profundizado en algunas ya abiertas - orientadas a centrar más el análisis en las desigualdades en el propio entorno de la pobreza, desarrollándose la perspectiva de género en el contexto de la consideración de los grupos especialmente vulnerables a la pobreza (personas solas, mujeres con cargas familiares o los niños ${ }^{32}$ ), y en analizar su comportamiento dinámico ${ }^{33}$. Se han

31 Sawyer (1976) realizó un estudio comparativo de la distribución de la renta para los países de la OCDE, utilizando los datos de la EPF de 1973-74. En términos de pobreza, el primer estudio comparado que incluye a España es el de O'Higgins y Jenkins (1989). Posteriormente, en Mercader-Prats (1993) se realiza una comparación de las poblaciones de baja renta en Francia, Reino Unido y España. Ayala et al. (1993) presentan un análisis detallado sobre comparaciones internacionales de pobreza utilizando la fuente de datos LIS — Luxembourg Income Study_, que reúne información procedente de encuestas de renta de unos veinticinco países para distintos años; y los mismos autores realizaron otro estudio tres años después en Ayala et al. (1996), donde analizaron los factores explicativos de la evolución de la desigualdad y la pobreza en España, centrándose en cuatro aspectos: la evolución del desempleo, la de los salarios, el efecto de los cambios socioeconómicos y los efectos redistributivos de las políticas públicas.

32 Respecto a la evolución de la pobreza infantil en España, desde principios de los setenta hasta principios de los noventa, ver Cantó y Mercader-Prats (1998); respecto a los jóvenes, ver Cantó y Mercader-Prats (1999, 2001); la relación entre las características socioeconómicas de los individuos y la pobreza se aborda en Toharia (1993) y Cantó (1997), centrándose especialmente en la relación entre el desempleo de los miembros del hogar y la situación económica familiar, y llegando a la conclusión de una alta correlación entre paro y pobreza.

33 Los primeros que se conocen son los de García y Toharia (1998) y Cantó (1996, 1998). Todos ellos utilizan encuestas longitudinales de familias a nivel nacional, para fines de los ochenta y principios de los noventa (el PHOGUE o la ECPF), procediendo a medir los flujos de entrada y de salida de la pobreza. La conclusión a la que se llega es que las diferencias entre pobres permanentes y pobres transitorios son de tipo educativo y de tamaño del hogar (a mayor nivel educativo del sustentador principal y menor tamaño del hogar, mayor probabilidad de salir de la pobreza), siendo las características laborales del sustentador principal más determinantes que las características demográficas. A nivel general, véase Rendtel y otros (1998). 
destacado, así, la «juvenilización» de la pobreza, la relativa indeterminación en la relación pobreza-empleo, la aparición de tasas de pobreza relevantes en niveles educativos medianos y altos, etc.

La perspectiva de género aborda el fenómeno de la «feminización» de la pobreza superando el enfoque meramente demográfico, que es el que ha primado, y que excluiría la posibilidad de mujeres pobres en hogares no pobres. En cualquier caso, son varios los estudios que, desde esa perspectiva "demográfica», señalan el profundo proceso de «feminización» de la pobreza, provocado sobre todo por el mayor riesgo de empobrecimiento que presentan aquellos hogares encabezados por mujeres. Sin embargo, existen muchas dificultades empíricas para conocer no sólo la situación de las mujeres en aquellos hogares en los que ellas son el principal sustentador, sino, y sobre todo, para conocer la problemática de las mujeres que viven en hogares por debajo del umbral de la pobreza e, incluso, la de aquellas mujeres que, aunque viven en hogares sin riesgo aparente, no tienen, sin embargo, acceso a los recursos económicos del cónyuge. Todas estas dificultades de sustento estadístico han desembocado en una falta de consenso respecto a la realidad de tal «feminización» de la pobreza, sobre la que se volverá al final del presente trabajo.

Respecto a la plasmación territorial de la pobreza (siempre de ingreso) en España, se confirma la concentración en algunas Comunidades Autónomas -Extremadura, Andalucía y Canarias-. Por otro lado, se han mantenido tasas inferiores a la media nacional en Madrid, Navarra y Cataluña, pero algunos estudios provinciales y municipales matizan las desigualdades en ese propio ámbito local (pobreza rural versus pobreza metropolitana) (Ayala y Renes, 1998).

\section{LA POBREZA HUMANA EN ESPAÑA}

El enfoque multidimensional de la pobreza exige una base empírica que, en el caso español, y en una perspectiva autonómica, se convierte en el principal obstáculo para su evaluación, agravado, además, en el propósito de incorporar el enfoque de género. Excepto la tasa de desempleo de larga duración, el resto de variables no se publican en las series estadísticas estándares ${ }^{34}$, por lo que, en nuestra investigación, la construcción de una base de datos para la construcción del IPH ha sido lenta y costosa. En dos casos —el Índice de

\footnotetext{
34 Para una descripción exhaustiva de las fuentes consultadas, incluyendo no sólo la selección final de datos, sino todos los que se han conocido en el proceso de búsqueda, se remite al texto íntegro de la investigación en Martínez Peinado et al. (2001). Los datos no utilizados se citan como aportación para posibles futuras investigaciones, dado que, a pesar de no servir para la construcción del IPH-2, pueden ser útiles para la elaboración de otro tipo de indicadores.
} 
Pobreza de Ingreso (IPI) y el Índice de Privación de Salud (IPS) 35 — la elaboración de los datos se ha tenido que encargar al Instituto Nacional de Estadística (INE), mientras que el Índice de Analfabetismo Funcional (IAF) ha requerido una aproximación muy rudimentaria a partir de los escasos estudios existentes al respecto en España ${ }^{36}$.

El concepto de alfabetización funcional merece un tratamiento especial. La definición que proporciona la OCDE (1997), a partir de la elaboración de la Primera Encuesta Internacional de Alfabetización de Adultos, contempla varias esferas de la misma: alfabetización de prosa, alfabetización de documentos y alfabetización cuantitativa ${ }^{37}$. Sin embargo, en los Informes del PNUD sólo se mide el analfabetismo funcional para el primer nivel (aptitud escasa) de alfabetización de prosa. Esta medición, además de incompleta, implica que el PNUD establece el analfabetismo funcional para aquellos países en los que se han realizado las encuestas pertinentes. Para el caso de España, al igual que para otros países desarrollados para los que no se dispone de la información real, el porcentaje de analfabetos funcionales que aparece en los Informes (16,8\%) está basado en la media de este tipo de analfabetismo en los países del norte de Europa, lo que, teniendo en cuenta las diferencias históricas, culturales y educativas, hace este dato poco creíble. Nuestro resultado, creemos

35 EI IPS fue calculado por el INE según las condiciones de mortalidad en cada Comunidad para el año de referencia (1997), así como según la estructura por edades de la población de ese año. En el cálculo del IPI se ha optado por el 50\% de la media del gasto, a pesar de que el PNUD opta por la variable del ingreso, dado que, como se ha señalado anteriormente, las fuentes estadísticas oficiales en España parecen caracterizarse por una mayor fiabilidad del gasto. Se utiliza el umbral del $50 \%$ en aras de la cautela y la comparabilidad con la mayoría de estudios en España, así como en consistencia con el umbral utilizado por el PNUD; y se opta por aplicar dicho umbral sobre la media del gasto, también para facilitar la comparabilidad con la mayoría de estudios en España que también utilizan esa medida, a pesar de que el PNUD prefiere aplicarlo sobre la mediana. Finalmente, se consideró más conveniente contabilizar los individuos que viven bajo el umbral de la pobreza en vez de contabilizar los hogares, ya que esta última opción se considera bastante inexacta (especialmente si se pretende, como era el caso del presente trabajo, poder llegar a incorporar la discriminación de género en la pobreza). Aunque las fuentes consultadas ofrecían bastante información cuantitativa sobre la pobreza de ingreso en general, no se disponía de las desagregaciones necesarias simultáneamente por género y por Comunidad Autónoma, por lo que hubo que optar —como ya se ha indicado— por encargar al INE la elaboración de los datos necesarios, quien la llevó a cabo a partir de la ECPF, base 1997 y el fichero longitudinal de 1998. Todo ello hace que, a la hora de tratar estos datos, se ha de tener en cuenta que los umbrales de pobreza solicitados se refieren al umbral nacional, para pasar después a estudiar el porcentaje de personas por CC.AA. y sexo que se encuentran por debajo del mismo.

${ }^{36} \mathrm{Ni}$ el INE ni ninguna otra institución asimilable elabora este dato, por lo que las cifras que se presentan en esta investigación (y que se utilizaron para calcular el IAF) son una elaboración propia realizada a partir de estudios no publicados (Flecha, 1993 y 1995). Para una descripción pormenorizada de los términos de esos trabajos, así como de los cálculos y estimaciones realizados, se remite al texto íntegro de la investigación de Martínez Peinado et al. (2001).

37 La Encuesta evaluó la destreza de alfabetización en tres esferas: i) la alfabetización de prosa, es decir, los conocimientos y aptitudes necesarios para comprender y utilizar la información de textos impresos, incluidos editoriales, artículos de noticias, poemas y ficción; ii) la alfabetización de documentos, que consiste en los conocimientos y aptitudes requeridos para ubicar y usar información en diferentes formatos, como las solicitudes de empleos, los formularios de nómina de pagos, calendarios de transporte, mapas, cuadros y gráficos; y iii) la alfabetización cuantitativa, conocimientos y aptitudes requeridos para aplicar operaciones aritméticas, ya sea por sí solas o en secuencia, a números incorporados en materiales impresos, ya sea saldar un talonario de cheques, calcular una propina, rellenar un formulario de pedido o determinar los intereses de un préstamo sobre la base de un aviso. 
que mucho más realista, apunta a una cifra sensiblemente superior, además de concluir que el analfabetismo funcional golpea más a las mujeres, en unos seis puntos a nivel general (de 100 analfabetos funcionales, 47 serían hombres y 53 mujeres) y unos diez puntos porcentuales intragénero (de cada 100 hombres, 20 son analfabetos funcionales, mientras las mujeres analfabetas funcionales son 30 de cada 100). En cualquier caso, la cifra de analfabetismo funcional total que se deriva es del $29 \%$, casi el doble a la que plantea el PNUD para España. Para recoger la desigualdad territorial, se parte de ese porcentaje y, manteniendo la dispersión ordinal reflejada en las encuestas de Flecha sobre el nivel educacional de cada Comunidad ${ }^{38}$, se ajusta (hacia arriba o hacia abajo) según presenten un nivel por encima o por debajo de la media estatal.

Respecto a las diferencias de género, la propuesta es usar los resultados de los IAF así establecidos adjudicándoles un punto más de analfabetismo adulto a las mujeres y uno menos a los hombres. Esto no tiene más justificación que la de recoger arbitrariamente las diferencias que se apuntan en los datos generales por género.

Finalmente, tal y como ya se ha señalado, la Tasa de Exclusión Social —la tasa de desempleo de larga duración - es la variable que menos problemas presenta a la hora de hallar los datos pertinentes. En este caso, el INE proporciona las cifras desglosadas a partir de la EPA y con media anual de $1997^{39}$.

Una vez elaborada la base de datos, el cálculo del IPH-2 para el Estado y las CC.AA. no ofrece mayores dificultades. Los resultados finales, así como de los índices componentes que se recogen en el cuadro 1 y en el mapa autonómico de la pobreza humana (mapa 1), dicen que el $19 \%$ de la población española se encuentra en situación de pobreza humana (casi dos de cada diez españoles/as), y a partir de ahí se dibujan cuatro espacios:

- Aquellas CC.AA. con menores índices de pobreza humana (es decir, por debajo del 19\% del Estado) se corresponden con la costa norte central (País Vasco, Cantabria y Asturias), así como Madrid y Baleares.

\footnotetext{
38 Algunos especialistas han planteado aproximar el analfabetismo funcional a través del porcentaje de población que no acaba la enseñanza secundaria, y así lo hace Flecha en su intento de aportar el desglose por Comunidades Autónomas.

39 Sin embargo, la facilidad en la obtención de datos no implica necesariamente que los valores de esta variable sean realmente representativos de la exclusión social medida en términos de desempleo de larga duración, ya que tradicionalmente los datos sobre esta cuestión están muy subestimados. Ello se debe fundamentalmente a dos factores: i) la bajísima tasa de actividad femenina en España; y ii) la poca fiabilidad, en general, de las estadísticas referentes al paro de larga duración, ya que éstas no contemplan a todas aquellas personas «desanimadas» que no se computan como población activa y, por lo tanto, ni como ocupadas ni como paradas. Todo ello lleva a pensar que las cifras utilizadas en el trabajo son sólo una estimación a la baja de lo que puede ser el fenómeno del paro de larga duración en España —especialmente para el caso de las mujeres- y, en definitiva, de lo que podría ser el fenómeno de exclusión social.
} 
- Los índices medianos-bajos (con valores entre un 19 y un 19,5\%) se presentan en Navarra, Cataluña y la Comunidad Valenciana.

- Los medianos-altos (con niveles entre un 19,5 y un 20'5\%) se presentan en La Rioja, las dos Castillas, Aragón, Canarias y Galicia.

- Por último, los índices más altos (superiores a un 20,5\%) se encuentran en el «amplio sur»: Andalucía (con un máximo absoluto del 20,93\%), Extremadura y Murcia.

MAPA 1

Índice de Pobreza Humana por Comunidades Autónomas

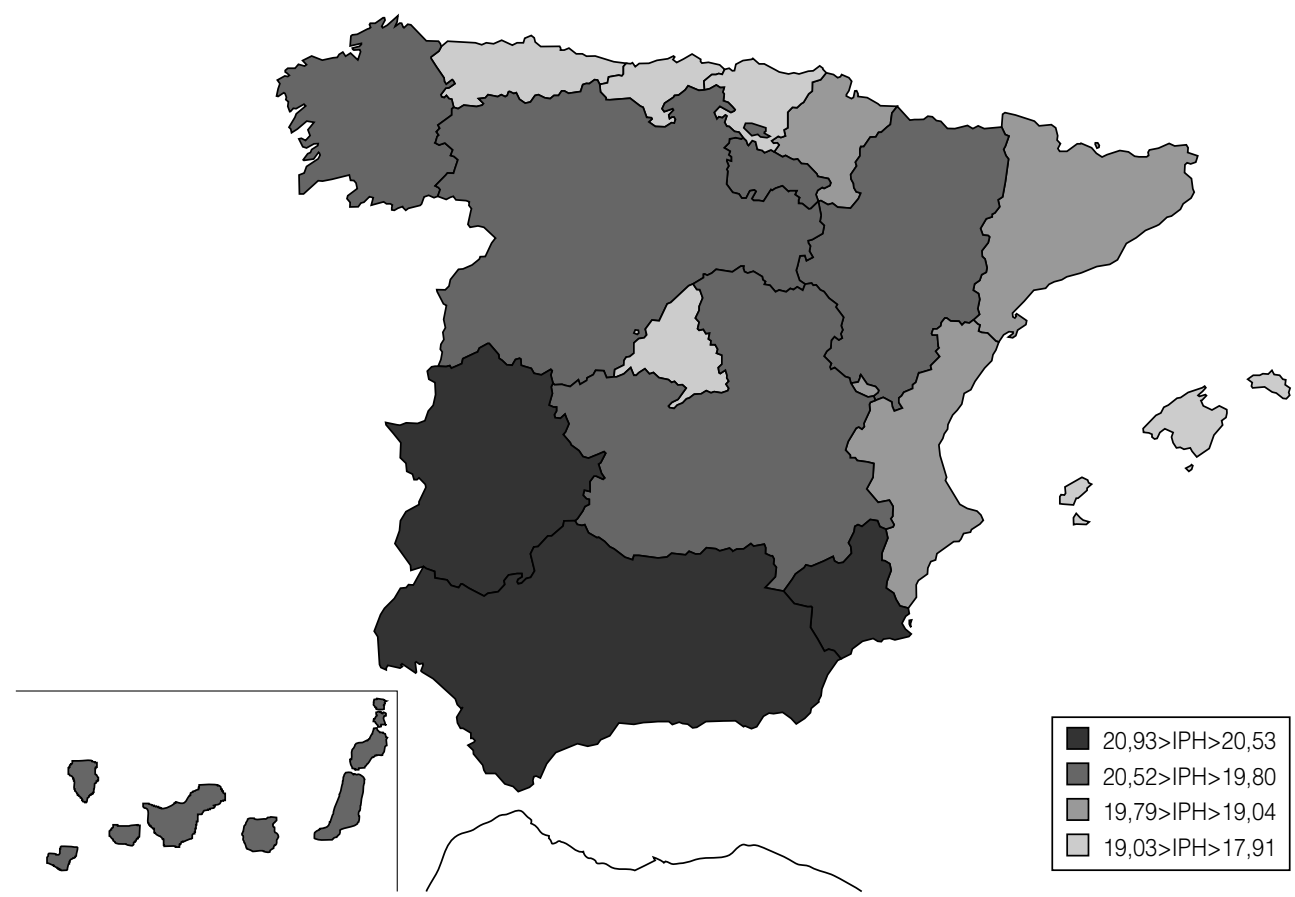

El análisis pormenorizado de los componentes del IPH para cada Comunidad Autónoma reviste mucha importancia, desde el punto de vista de la identificación de áreas de actuación sobre las que centrar las eventuales políticas que se puedan definir para erradicar -o cuando menos paliar - la pobreza humana en cada una de ellas. En el cuadro 2 se puede constatar que se dan considerables discrepancias en las clasificaciones de las CC.AA. se- 
CUADRO 1

Índice de Pobreza Humana en España y las Comunidades Autónomas

\begin{tabular}{lrrrrr} 
& $\begin{array}{r}\text { Pnalfa- } \\
\text { Privación } \\
\text { de salud }\end{array}$ & $\begin{array}{r}\text { betismo } \\
\text { funcional }\end{array}$ & $\begin{array}{r}\text { Exclusión } \\
\text { social }\end{array}$ & $\begin{array}{r}\text { Pobreza } \\
\text { de ingreso }\end{array}$ & IPH \\
\hline Andalucía & 7,85 & 32 & 11,57 & 12,36 & 20,93 \\
Aragón & 6,57 & 31 & 3,29 & 11,75 & 19,94 \\
Asturias & 7,73 & 29 & 7,76 & 10,89 & 18,81 \\
Islas Baleares & 7,48 & 29 & 3,25 & 8,94 & 18,56 \\
Canarias & 8,73 & 30 & 8,02 & 14,46 & 19,83 \\
Cantabria & 7,14 & 28 & 7,09 & 10,62 & 18,14 \\
Castilla y León & 6,28 & 31 & 5,86 & 12,88 & 20,08 \\
Castilla-La Mancha & 6,69 & 31 & 5,33 & 10,55 & 19,88 \\
Cataluña & 6,80 & 30 & 6,40 & 8,84 & 19,19 \\
Comunidad Valenciana & 7,39 & 30 & 7,12 & 11,90 & 19,45 \\
Extremadura & 7,38 & 31 & 8,18 & 15,73 & 20,53 \\
Galicia & 7,73 & 31 & 7,29 & 12,45 & 20,12 \\
Comunidad de Madrid & 6,38 & 29 & 8,48 & 10,94 & 18,80 \\
Región de Murcia & 7,16 & 32 & 6,61 & 11,88 & 20,63 \\
Comunidad Foral de Navarra & 6,19 & 30 & 2,32 & 7,22 & 19,04 \\
País Vasco & 6,96 & 28 & 7,22 & 6,71 & 17,91 \\
La Rioja & 6,24 & 31 & 3,15 & 9,99 & 19,80 \\
ESPAÑA & 7,08 & 29 & 7,60 & 13,64 & 19,07
\end{tabular}

gún los diferentes componentes, así como la resultante según el IPH. Tales diferencias pueden observarse en los gráficos 1 y 2 , en los que se ha representado la posición que ocupan algunas CC.AA. según cada uno de los componentes, excepto el IAF, por la escasez de información respecto al nivel de analfabetismo funcional y la metodología seguida para su elaboración (aunque tampoco parece existir base empírica para modificar —al menos a la baja - los resultados globales, que expresan la importancia máxima cuantitativa de este componente en el IPH-2, reflejo a su vez de la significación del alfabetismo funcional en la famosa «sociedad del conocimiento» $)^{40}$.

40 En el segundo apartado de este artículo se ha hecho referencia a algunos estudios, realizados en España, que se han centrado en la relación entre el nivel de estudios del cabeza de familia y la situación de pobreza de la misma, llegándose a la conclusión que la relación es muy fuerte. Sin embargo, tal y como también se ha señalado anteriormente, el término de analfabeto funcional es más complejo y requiere de otro tipo de información, diferente a la proporcionada por los niveles de escolarización. 
CUADRO 2

Posiciones por Comunidades Autónomas según los índices componentes

\begin{tabular}{|c|c|c|c|c|c|}
\hline CC.AA. & IES & IAF & IPI & IPS & $\mathrm{PH}$ \\
\hline Andalucía & 1 & 1 & 5 & 2 & \\
\hline Región de Murcia & 10 & 2 & 7 & 8 & 2 \\
\hline Extremadura & 3 & 6 & 1 & 7 & 3 \\
\hline Galicia & 6 & 7 & 4 & 4 & 4 \\
\hline Castilla y León & 12 & 5 & 3 & 15 & 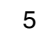 \\
\hline Aragón & 14 & 3 & 8 & 13 & 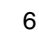 \\
\hline Castilla-La Mancha & 13 & 4 & 12 & 12 & 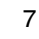 \\
\hline Canarias & 4 & 10 & 2 & 1 & 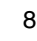 \\
\hline La Rioja & 16 & 8 & 13 & 16 & 9 \\
\hline Comunidad Valenciana & 8 & 12 & 6 & 6 & 10 \\
\hline Cataluña & 11 & 11 & 15 & 11 & 11 \\
\hline Comunidad Foral de Navarra & 17 & 9 & 16 & 17 & 12 \\
\hline Asturias & 5 & 13 & 10 & 3 & 13 \\
\hline Comunidad de Madrid & 2 & 14 & 9 & 14 & 14 \\
\hline Islas Baleares & 15 & 15 & 14 & 5 & 15 \\
\hline Cantabria & 9 & 16 & 11 & 9 & 16 \\
\hline País Vasco & 7 & 17 & 17 & 10 & 17 \\
\hline
\end{tabular}

En el gráfico 1 se presentan las CC.AA. que «lideran» alguna de las clasificaciones, bien de los componentes (IES, IPI o IPS), bien del IPH final. Como puede comprobarse, no hay una homogeneidad en el comportamiento posicional en este grupo de «menos favorecidos», ya que Murcia, sin ocupar la primera posición en ninguna de las clasificaciones y ocupando la segunda en dos de ellas (el IPH y el IAF), presenta sin embargo una posición bastante más desahogada en términos de privación de ingreso y de salud, pero sobre todo de exclusión social. Por consiguiente, su mal comportamiento en términos de privación humana obedece fundamentalmente (como puede comprobarse en el cuadro 1) a su indicador en analfabetismo funcional. El caso de Andalucía, en el otro extremo, ofrece un comportamiento más homogéneo, presentando las peores clasificaciones en casi todos los componentes, a excepción de la pobreza de ingreso, donde arroja una posición menos extrema. Extremadura y Canarias presentan, por su parte, comportamientos más erráticos.

Por lo que respecta a aquellas CC.AA. que presentan los menores niveles de privación en cualquiera de las clasificaciones (País Vasco, Navarra, Cantabria, La Rioja y Baleares), también en ellas se observan grandes heterogeneidades en las posiciones, llegando algunas a presentar peores clasificaciones que las de las CC.AA. del gráfico1 (tal es el caso del País Vasco y Cantabria respecto de Murcia, en materia de exclusión social; y el de Baleares respecto de Murcia y Extremadura, en privación de salud). De hecho, en términos de 
GRÁFICO 1

Posición componentes de las Comunidades Autónomas con mayores niveles de privación

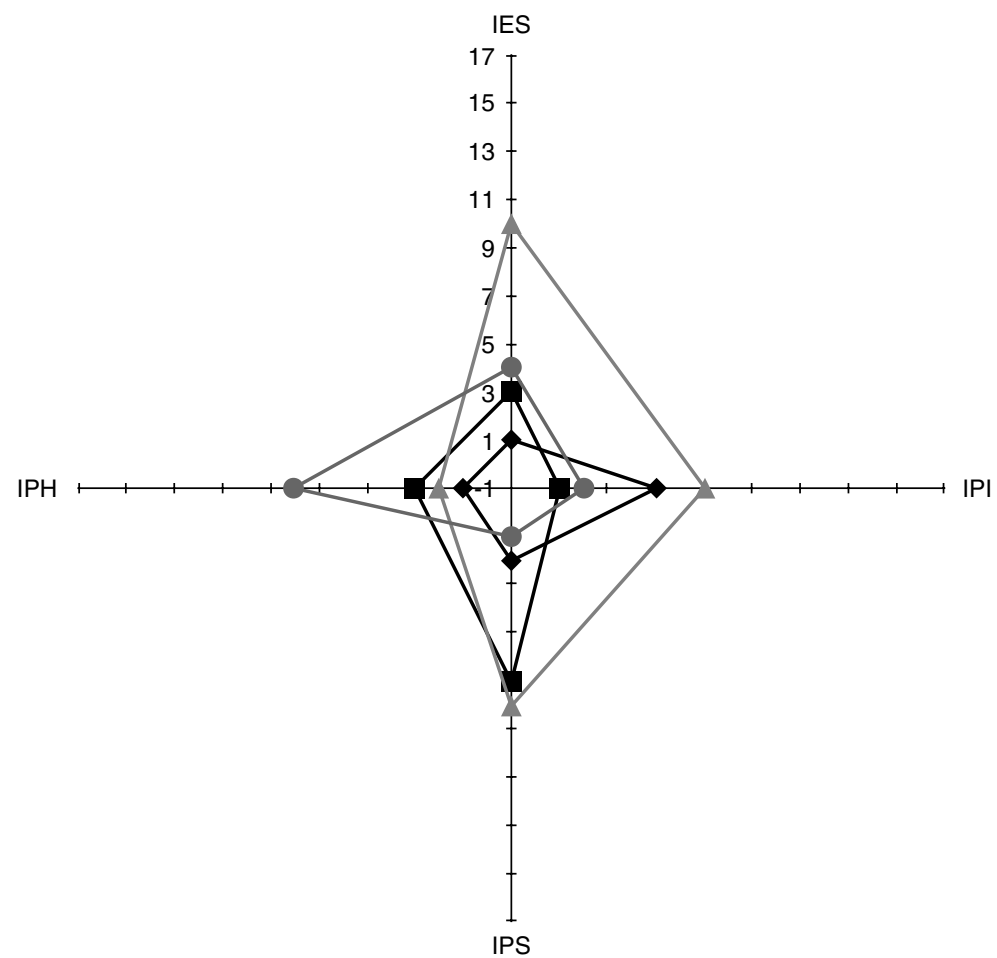

$\neg$ Andalucía $\rightarrow-$ Extremadura $\rightarrow-$ Murcia - Canarias

pobreza humana, Canarias ocupa la octava posición, mientras que La Rioja es la contigua, ocupando el noveno lugar. En el gráfico 2 se han representado gráficamente las posiciones que ocupan el País Vasco y La Rioja. El caso del País Vasco, último lugar en el IPH, sirve para ilustrar el mayor nivel de correlación del IPH con el IAF y el IPI que con los otros componentes, ya que, a pesar de presentar esta Comunidad unos altos niveles de exclusión social y de privación de salud, ocupa sin embargo esa última posición en pobreza humana gracias a los buenos resultados en términos de analfabetismo funcional y de pobreza de ingreso. El caso de La Rioja también es ilustrativo de lo mismo, aunque a la inversa, ya que son sus malas clasificaciones en términos de esos dos componentes las que le hacen descender a la novena posición del IPH, a pesar de ocupar el penúltimo lugar tanto en privación de salud como de exclusión social. 
GRÁFICO 2

Posición componentes País Vasco y La Rioja

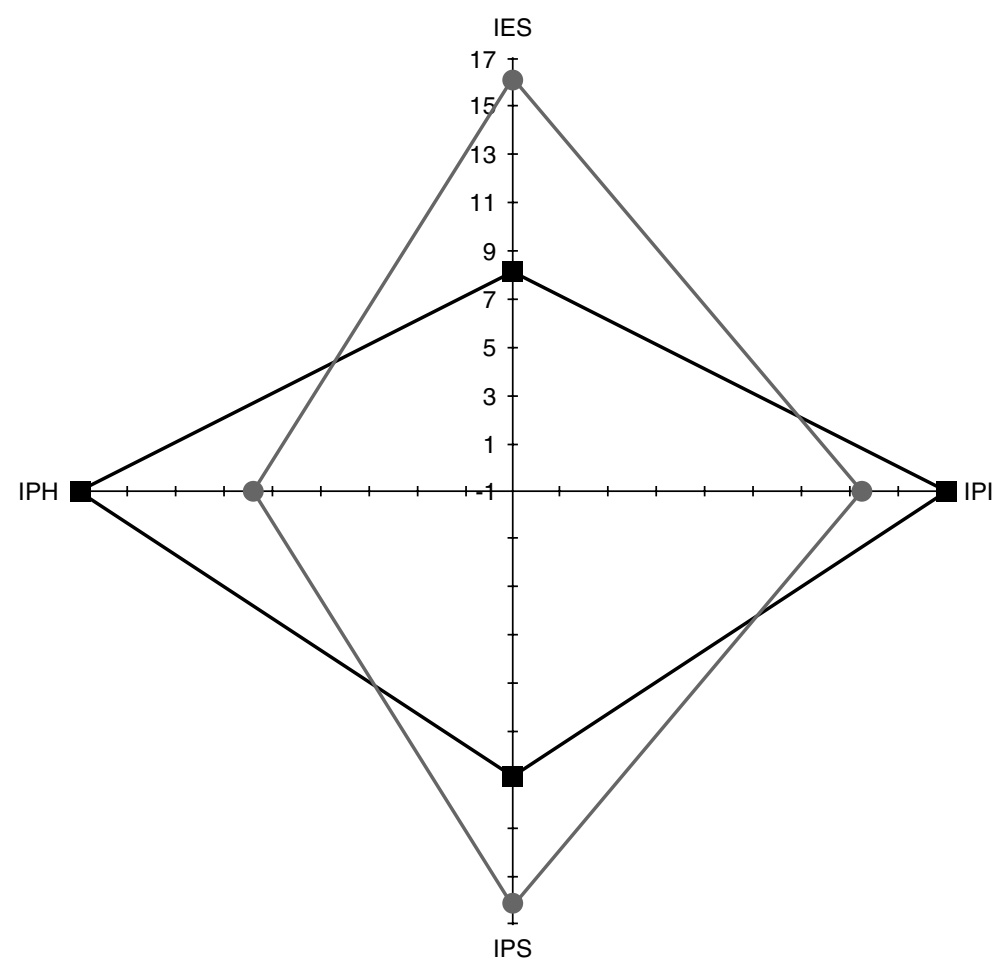

$\rightarrow$ País Vasco - La Rioja

En definitiva, a partir de los datos vistos hasta el momento se pueden establecer los mapas autonómicos de los diferentes componentes de la pobreza humana, que complementen al realizado a nivel general en términos de pobreza humana en el apartado anterior. Para cada componente los resultados son los siguientes:

i) Privación de salud: Se observa que afecta a poco más del 7\% de la población en España. Por CC.AA.:

- Hay nueve Comunidades que se sitúan por encima de esa media, entre las que hay que situar al «gran sur» (Andalucía, Murcia y Extremadura), a los dos archipiélagos (Baleares 
y, sobre todo, Canarias, con un máximo estatal del 8,73\%) y a gran parte del norte peninsular (Galicia, Asturias y Cantabria), además de la Comunidad Valenciana.

- Las ocho Comunidades restantes se sitúan por debajo del 7\%, aunque cuatro (País Vasco, Cataluña, Castilla-La Mancha y Aragón) están por encima del 6,5\%, y las cuatro restantes (Madrid, Castilla y León, La Rioja y Navarra, con el mínimo estatal de un 6,19\%) se sitúan por debajo de dicho baremo.

ii) Privación de conocimientos: Sobre una media española del 29\%, la metodología utilizada para el cálculo del IAF hace que las diferencias entre las CC.AA. no sean demasiado grandes, moviéndose entre el máximo del 32\% de Andalucía y Murcia y el mínimo del 28\% para una parte del norte peninsular (Cantabria y País Vasco).

iii) Exclusión social: Afecta a un 7,6\% de la población total. Por CC.AA.:

- Cinco CC.AA. superan dicha media, destacando en primer lugar Andalucía, con un $11,75 \%$, seguida de Madrid, Extremadura, Canarias y Asturias.

- Otras cuatro (Galicia, País Vasco, Valencia y Cantabria) presentan niveles entre el 7 y el $7,6 \%$.

- Cuatro más arrojan niveles entre el 5 y el 7\%, que son: Murcia, Cataluña, Castilla y León y Castilla-La Mancha.

- Finalmente, hay cuatro CC.AA. que no superan el 3,3\%: Aragón, Baleares, La Rioja y, sobre todo, Navarra, con el mínimo absoluto del 2,32\%.

iv) Privación de ingreso: Por último, la pobreza de ingreso alcanza al 13,64\% del total de la población española. Por CC.AA.:

- Sólo dos Comunidades superan tal promedio: Extremadura, con un 15,73\%, y Canarias, con el $14,46 \%$ de su población por debajo del umbral de pobreza de ingreso.

- Por debajo de la media pero por encima del $11 \%$ se sitúan Castilla y León, Galicia, Valencia, el resto del «gran sur» (Andalucía y Murcia) y Aragón.

- Entre el 9 y el 11\% hay cinco Comunidades: Madrid, Asturias, Cantabria, Castilla-La Mancha y La Rioja.

- Finalmente, con valores inferiores al $9 \%$ hay que señalar a Baleares, Cataluña, Navarra y País Vasco, con el mínimo estatal del 6,71\%. 
También vale la pena destacar que los mayores niveles de dispersión, es decir, las mayores diferencias entre los comportamientos de las diferentes CC.AA., se observan en el IES y en el IPI, para los cuales la dispersión supera a los 9 puntos porcentuales. El IPS presenta el menor nivel de dispersión (en torno a los 2 puntos y medio porcentuales), seguido del propio IPH (con casi 4 puntos porcentuales) y el IAF, que alcanza esos 4 puntos porcentuales de variación máxima.

Dado que el IPH pretende ser un indicador alternativo a la medición de la pobreza exclusivamente en términos de ingreso, resulta especialmente importante comparar los resultados obtenidos según ambos indicadores. Como se acaba de ver (dejado al margen el IAF), el IPI es el componente que más influye en el resultado final del IPH; sin embargo, es destacable la importante diferencia entre los resultados globales para España a partir de ambos indicadores. Así, mientras que los resultados obtenidos certifican que en España, en 1997, había un 13,64\% de individuos pobres de ingreso, tal proporción se eleva en más de 5 puntos porcentuales, alcanzando algo más del 19\%, si se mide la pobreza en términos del paradigma del desarrollo humano ${ }^{41}$. De ello puede deducirse que la pobreza humana

\section{GRÁFICO 3}

\section{Correlación IPH-IPI}

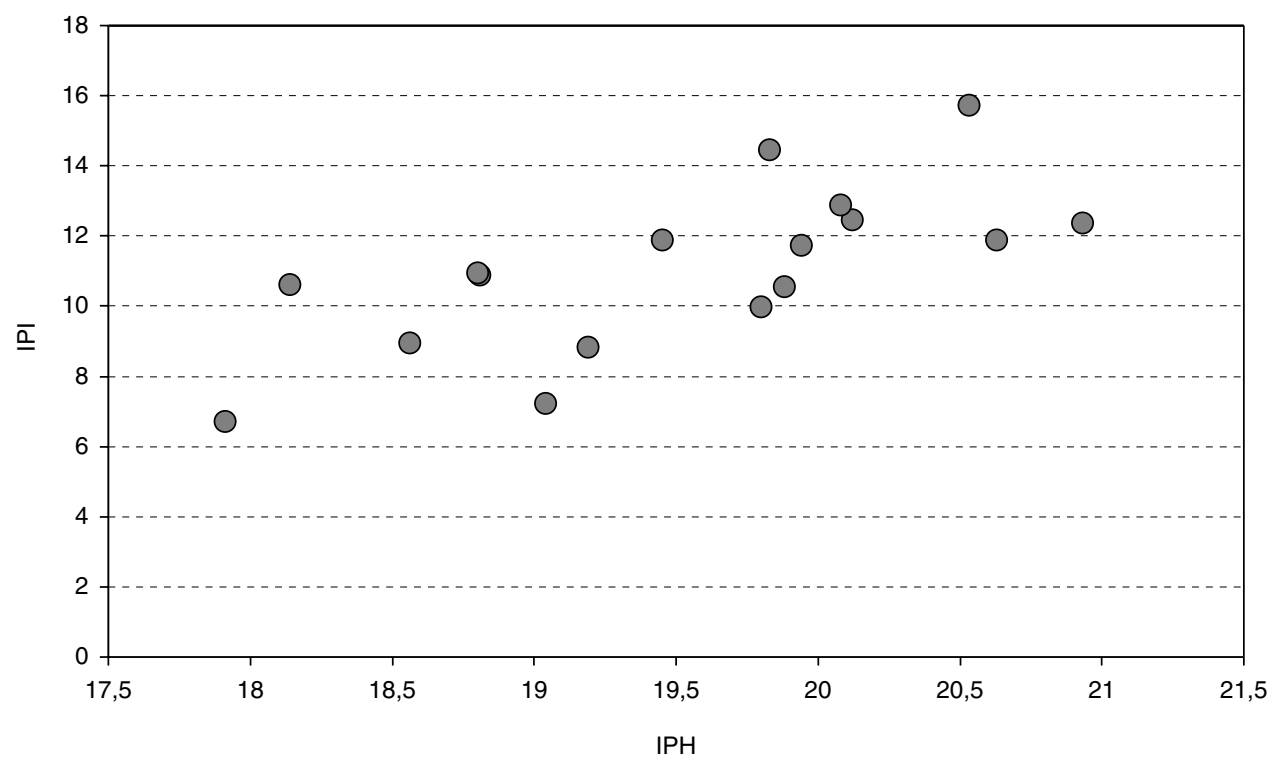

41 La correlación entre el IPH y el IPI puede comprobarse en el gráfico 3. 
no se agota en la pobreza de ingreso (a pesar de que se vea influida poderosamente por ella) y que es necesario contemplar las otras dimensiones que la componen; lo cual tiene un enorme potencial, como ya se ha indicado, desde el punto de vista de formulación de políticas, al identificar los factores de privación sobre los que se precisa actuar.

Por CC.AA., tal y como queda reflejado en el gráfico 4, sólo dos Comunidades mantienen su puesto en las respectivas clasificaciones según los dos indicadores: Galicia, que ocupa la cuarta posición, y el País Vasco, que se sitúa en el último lugar, es decir, con el menor nivel de pobreza según ambos criterios. De las quince Comunidades restantes, siete empeoran su clasificación según el IPH respecto del lugar que ocupan según el criterio de la pobreza de ingreso (Aragón pierde dos posiciones; Andalucía, La Rioja, Cataluña y Navarra pierden cuatro; mientras que Murcia y Castilla-La Mancha llegan a perder cinco posiciones), y las otras ocho la mejoran (Baleares tan sólo gana una posición; Extremadura y Castilla y León ganan dos; Asturias, tres; Valencia, cuatro; Madrid y Cantabria ganan cinco lugares; y, por último, Canarias gana seis). Por consiguiente, las clasificaciones relativas son sensiblemente diferentes.

GRÁFICO 4

Comparación clasificación Comunidades Autónomas según IPI y según IPH

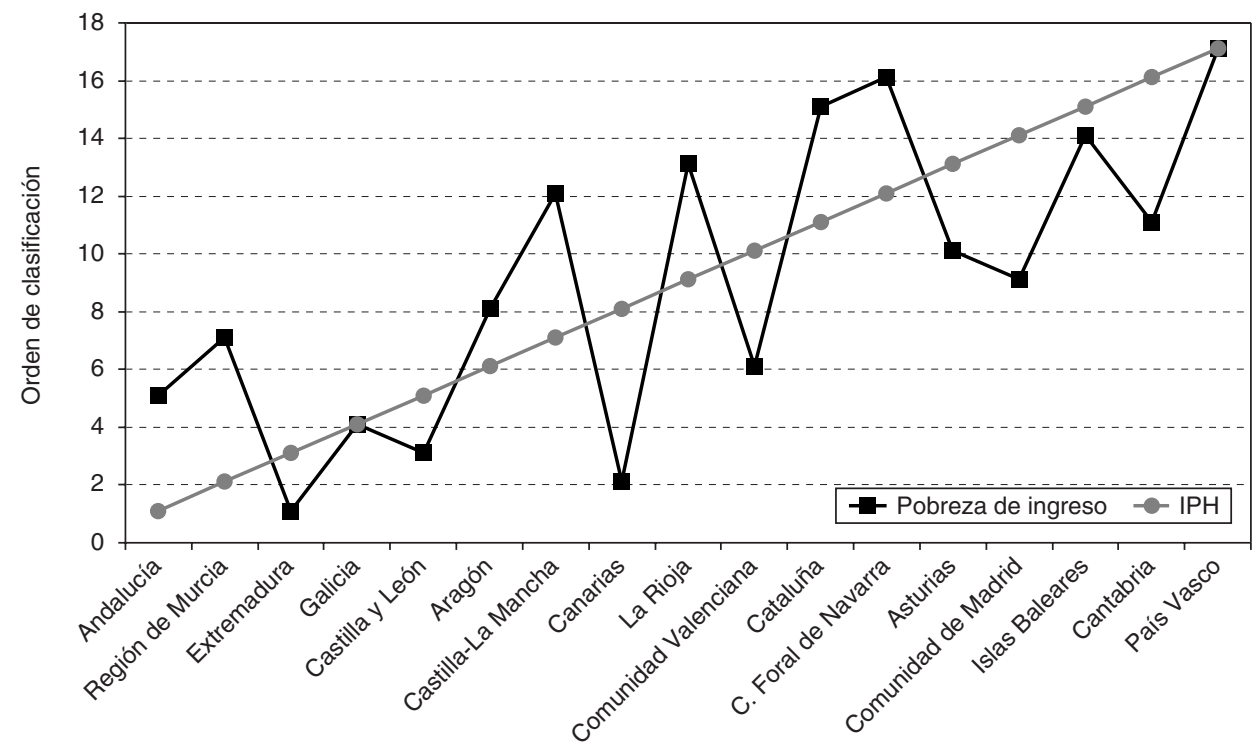


En definitiva, la pobreza humana, en términos relativos autonómicos, no tiene el mismo mapa que la pobreza de ingreso, única contemplada en los estudios hasta la fecha.

\section{LA FEMINIZACIÓN DE LA POBREZA EN ESPAÑA}

Uno de los objetivos de nuestra investigación ha sido la evaluación de la pobreza humana en España incorporando su nivel de feminización. Dado que el PNUD todavía no ha especificado ningún método para hacerlo, se optó por proponer una metodología en este sentido, siguiendo la lógica del paradigma de incorporar — que no medir directamente- la discriminación de la mujer a los índices propuestos ${ }^{42}$. Los resultados se recogen en el cuadro 3.

Se pretende reflejar dónde y por qué las mujeres españolas sufren un mayor nivel de privaciones, así como identificar los ámbitos de privación dominantes en lo que se refiere a las mujeres. En términos generales, las desigualdades en los niveles de pobreza de las mujeres respecto a los de los hombres se combinan con las diferencias entre CC.AA. El peso principal en el IPHG lo tiene el analfabetismo funcional (al igual que en el caso del IPH), mientras que la discriminación de género se basa sobre todo en la exclusión social. En consecuencia, tanto en el nivel general autonómico como en el específico entre géneros, ambos componentes son los que explican los rasgos fundamentales de la feminización de la pobreza.

Las conclusiones más significativas del análisis realizado pueden resumirse en las siguientes:

1. ${ }^{a} \quad$ La mujer sufre más privaciones que el hombre en situación de pobreza, dado que las tasas de pobreza humana que incorporan las diferencias de género (IPHG) son siempre mayores que las tasas de pobreza humana globales (IPH). Por ello, la pobreza humana global en España y en las CC.AA. experimenta un aumento al incorporar el enfoque de género a su medición. Por consiguiente, la hipótesis de feminización de la pobreza queda validada por los resultados obtenidos, tanto en España como en todas las CC.AA. Eso quiere

\footnotetext{
42 La metodología aplicada sigue, por tanto, la pauta de lo realizado en el cálculo del IDG, a partir del IDH, a la hora de incorporar la discriminación de género. Sin embargo, dado que en el ámbito de la pobreza no se están considerando los logros, sino las privaciones, si hay discriminación de género, las privaciones son mayores en las mujeres que en los hombres. Consecuentemente, tal discriminación se tiene que incorporar mediante la aplicación no de medias armónicas (que destacan los valores más bajos), como es el caso en la elaboración del IDG, sino a través de las medias aritméticas o de las medias cuadráticas (estadísticos que destacan los valores más altos, sobre todo esta última). Finalmente se optó por la aritmética, por su mayor sencillez y para compensar los valores más bajos de las mujeres en términos de privación de salud. En definitiva, el procedimiento consiste en tres pasos: i) cálculo, para cada componente, de las medias aritméticas de los porcentajes masculino y femenino; ii) ponderación de dichas medias con la composición por sexos de la población; y iii) cálculo del IPHG-2 como la media cúbica de los índices componentes ponderados.
} 
decir que, como sujeto especial de pobreza, la mujer debiera ser también el sujeto específico de políticas al respecto.

2. ${ }^{a} \quad$ Sin embargo, dichos aumentos en los niveles de privación difieren según las CC.AA.; así, algunas Comunidades sufren más ese incremento que otras, en la medida en que los niveles de privaciones de las mujeres pobres no se diferencian tanto de los de los hombres pobres.

CUADRO 3

Índice de Pobreza Humana e Índice de Pobreza Humana relativo al Género y sus componentes

\begin{tabular}{|c|c|c|c|c|c|c|}
\hline CC.AA. & $\mathrm{IPH}$ & IPSg & IAFg & IESg & IPlg & IPHG \\
\hline Andalucía & 20,93 & 8,18 & 33,11 & 12,71 & 12,70 & 21,71 \\
\hline Galicia & 20,12 & 8,43 & 33,31 & 8,06 & 12,67 & 21,56 \\
\hline Región de Murcia & 20,63 & 7,43 & 33,00 & 7,17 & 12,06 & 21,26 \\
\hline Extremadura & 20,53 & 7,57 & 31,66 & 9,17 & 15,24 & 20,89 \\
\hline Castilla y León & 20,08 & 6,49 & 31,85 & 6,54 & 12,52 & 20,57 \\
\hline Aragón & 19,94 & 6,90 & 31,99 & 3,65 & 10,83 & 20,49 \\
\hline Canarias & 19,83 & 8,88 & 30,43 & 8,51 & 16,44 & 20,39 \\
\hline Comunidad Valenciana & 19,45 & 7,80 & 31,36 & 7,77 & 12,70 & 20,38 \\
\hline Comunidad de Madrid & 18,81 & 6,98 & 31,26 & 9,60 & 12,17 & 20,32 \\
\hline Asturias & 18,80 & 8,54 & 31,39 & 8,90 & 10,86 & 20,32 \\
\hline La Rioja & 19,80 & 6,43 & 31,78 & 3,52 & 8,84 & 20,22 \\
\hline Castilla-La Mancha & 19,88 & 6,81 & 31,48 & 6,00 & 9,31 & 20,11 \\
\hline Cataluña & 19,19 & 7,18 & 31,36 & 6,92 & 8,05 & 20,01 \\
\hline Comunidad Foral de Navarra & 19,04 & 6,30 & 30,45 & 2,52 & 6,60 & 19,31 \\
\hline Islas Baleares & 18,56 & 7,83 & 30,12 & 3,48 & 7,88 & 19,21 \\
\hline País Vasco & 17,91 & 7,34 & 29,77 & 7,85 & 7,51 & 19,05 \\
\hline Cantabria & 18,14 & 7,57 & 29,33 & 7,80 & 10,31 & 18,95 \\
\hline ESPAÑA & 19,07 & 7,47 & 30,29 & 8,35 & 14,00 & 19,90 \\
\hline
\end{tabular}

El mapa autonómico de pobreza humana relativa al género (mapa 2) muestra cómo la incorporación del enfoque de género redibuja el mapa 1. Así, Galicia se une a Extremadura, Andalucía y la Región de Murcia en los mayores niveles de pobreza; la Comunidad Valenciana se incorpora al peor segundo grupo; la Comunidad de Madrid y Asturias lo hacen al tercero (cuando estaban en el grupo menos pobre en términos de pobreza humana general). Sólo La Rioja, la Comunidad Foral de Navarra y Castilla-La Mancha mejoran su posición relativa, pasando a formar parte de los grupos inmediatamente mejores a los que pertenecen según el nivel general de pobreza humana. 
MAPA 2

Índice de Pobreza Humana de Género por Comunidades Autónomas

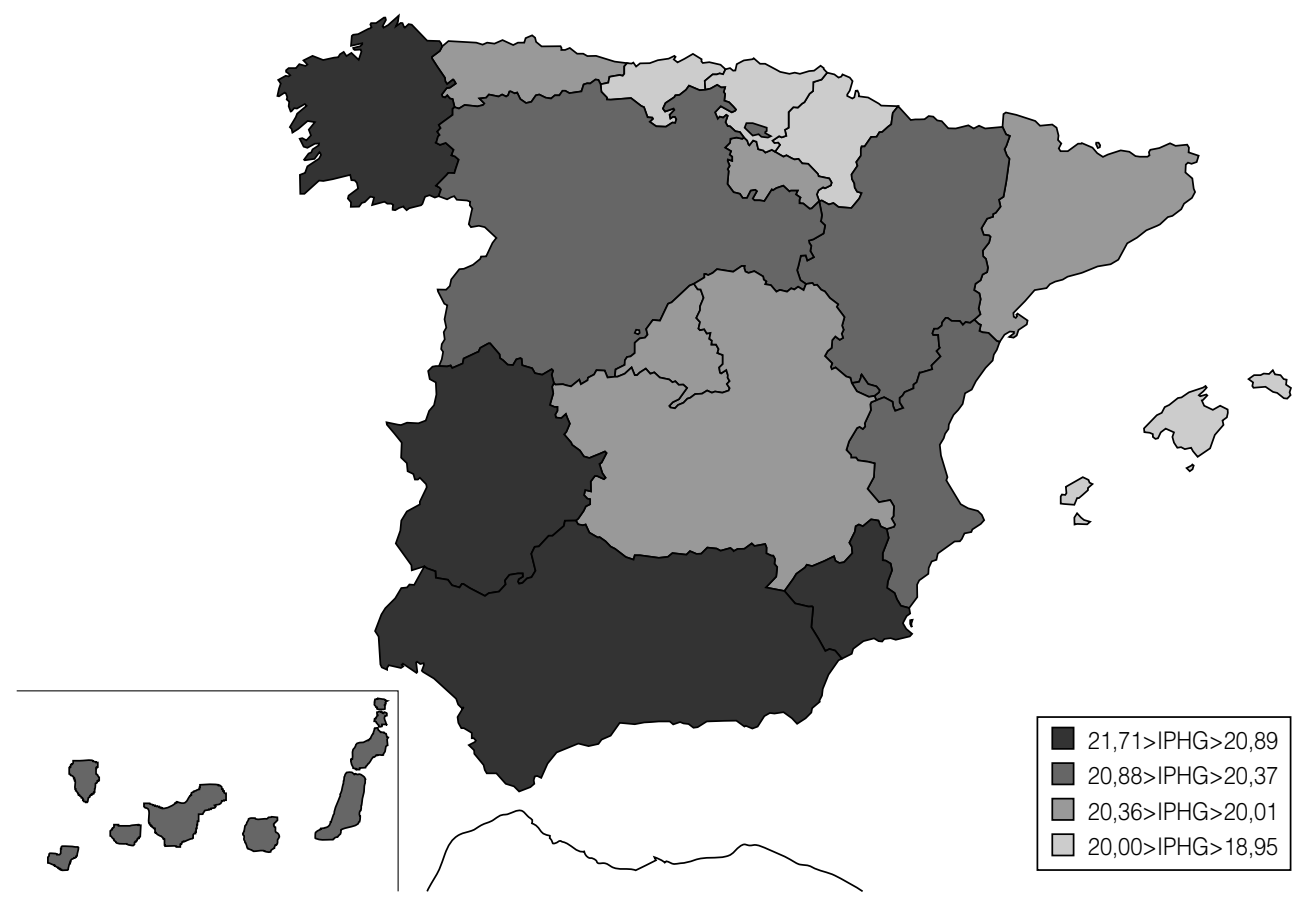

En definitiva, el IPHG califica mejor al IPH, al penalizarlo según la condición de la mujer pobre, aunque con diferencias autonómicas significativas.

3. ${ }^{\text {a }}$ En la aportación de los componentes del IPHG, el analfabetismo funcional es el que explica más el nivel final de pobreza de género. Ello es debido a la magnitud de su valor, ya que los porcentajes de analfabetos funcionales son muy superiores a las tasas de pobreza de ingreso o a las tasas de desempleo de larga duración. Sin embargo, son estas últimas, o sea, los índices de exclusión social, las que mejor incorporan la disparidad de género entre los pobres. En cualquier caso, las CC.AA. presentan un comportamiento también muy complejo (y de difícil sistematización) al considerar sus posiciones relativas por cada componente.

4. ${ }^{\text {a }} \quad$ Las disparidades de género en cada componente dependen extraordinariamente de los datos usados y de las elaboraciones a partir de ellos. Es muy perceptible una discrimi- 
nación positiva (a favor de las mujeres) en la privación de salud; un cierto mayor grado de analfabetismo funcional en las mujeres (difícilmente evaluable); una clara feminización de la exclusión social, basada tanto en las mayores tasas de desempleo de larga duración como en la menor participación en el mercado laboral (la «doble exclusión social» de las mujeres); y una ambivalencia en la pobreza de ingreso, fundamentada en la dificultad empírica de separar por género los ingresos o gastos de los hogares pobres.

5. ${ }^{\text {a }} \quad$ Aunque muestra la efectiva feminización de la pobreza, el IPHG propuesto (utilizando medias aritméticas de los componentes de privación) lo hace de una forma bastante liviana, y desde la óptica, propia del paradigma del desarrollo humano, de incorporar la desigualdad de género al nivel general de privaciones, agravándolas. Es posible, bien ajustando algunas de las variables que entran en el índice, bien cambiando el modelo (medias cuadráticas, cocientes), obtener indicadores alternativos, que, en general, implican mayores niveles de pobreza al considerar el género, aunque no tanto cambios en las posiciones relativas de las CC.AA. ${ }^{43}$. El dilema de incorporar o medir directamente la desigualdad, dadas las restricciones empíricas, se resuelve en este caso porque lo único que cambia (en sentido creciente) son los valores, que hacen empeorar los índices de pobreza humana de las comunidades, pero no su situación en el contexto estatal (excepto en el caso de Canarias, que mejora su posición al medir directamente la desigualdad respecto a la mera incorporación de la misma, ya que es de las Comunidades donde menos se da la feminización de la pobreza).

\section{CONCLUSIONES Y RECOMENDACIONES}

A pesar de las limitaciones empíricas, una primera conclusión emerge con fuerza: es fundamental enfocar la pobreza como pobreza humana, multidimensional, no sólo de ingreso. En este sentido, el nuevo paradigma del PNUD ofrece un amplio campo de actuación. Ello plantea, entonces, la necesidad de formular recomendaciones metodológicas y políticas al respecto.

En segundo lugar, cabe concluir también que no es posible hablar seriamente de pobreza en España sin introducir la perspectiva de género, porque, a pesar de las limitaciones esta-

\footnotetext{
43 Para estos índices alternativos remitimos de nuevo a la investigación original. Cabe resaltar de nuevo que el presente artículo se ha circunscrito a la feminización de la pobreza humana. No se han tomado en consideración, por tanto, los ámbitos de discriminación recogidos por otros indicadores de género propuestos por el PNUD, como el IDG (que contempla las diferencias en esperanza de vida, nivel educativo e ingreso) o el IPG (Índice de Potenciación de Género, que contempla la discriminación en la participación política y poder de decisión, en la participación económica y poder gerencial y en los recursos económicos). Pueden verse, al respecto, las ediciones citadas del PNUD. Para el caso español, P. de Villota ha realizado diversas aproximaciones, pero es un tema que desborda el interés del presente trabajo.
} 
dísticas, que son las que reducen la evaluación numérica de los índices de pobreza, se hace evidente que cualquier avance en el campo de los datos redundaría en un agravamiento de los indicadores.

En tercer lugar, cabe plantearse la exigencia de unas estadísticas pertinentes como una necesidad no sólo metodológica, sino de carácter político, ya que sin un conocimiento fáctico las políticas antipobreza pueden ser auténticos palos de ciego. Así:

- En una sociedad como la actual, en la que las nuevas tecnologías y la elaboración y absorción de información se han convertido en factores definitorios del progreso y bienestar, el analfabetismo funcional se convierte en pieza clave en la exclusión económica y social, en la privación de capacidades y oportunidades para mejorar el nivel de vida o, al menos, no empeorarlo definitivamente y sin remedio, cayendo en situaciones de pobreza. Y, sin embargo, no hay datos...

- En una sociedad como la española, en la que la mujer tiene muchas dificultades para su incorporación plena e igualitaria a la esfera productiva, es fundamental conocer precisamente esas dificultades para poder contrarrestarlas con políticas específicas: la estructura sectorial del desempleo femenino, las razones de la inactividad de las mujeres, la precariedad adicional por el hecho de ser mujer (maternidad, cuidados de familiares mayores), etc. Y, sin embargo, no hay muchos datos de registros...

- En los hogares pobres es muy posible que la mujer sufra una discriminación de ingreso o gasto respecto a los hombres. Además, mientras que en el ámbito del desarrollo humano la esfera productiva puede suplir algunos aspectos de la reproductiva (y, con empleo remunerado, la mujer puede aminorar la discriminación en la esfera doméstica), en el ámbito de la pobreza no ocurre lo mismo, porque precisamente la mujer está más excluida del mercado de trabajo que el hombre, tiene menos capacidades y oportunidades para encontrar trabajo externo remunerado, y tiene a su cargo con más intensidad los cuidados de la familia. Y sobre todo ello, sin embargo, hay pocos datos...

Hay expectativas de mejoras estadísticas, en el marco de las iniciativas de la Unión Europa. Seguramente, pues, futuros estudios podrán contar con una mejor base empírica que permita diseñar mejor las políticas contra el analfabetismo funcional, contra la exclusión social, contra la pobreza de ingreso, desde un punto de vista de género, y contra la privación de salud (que puede reflejarse empíricamente con variables como la «esperanza de vida libre de discapacidad» y otras referidas a la morbilidad), desde un punto de vista general ${ }^{44}$. Por lo

44 A este respecto, B. Sutcliffe: «Desarrollo humano y muerte», en Ibarra y Unceta (2001). 
que se sabe hasta ahora, y a tenor de los indicadores de pobreza humana elaborados en esta investigación, la orientación de las políticas debería asumir dicha perspectiva de pobreza humana y abarcar las múltiples dimensiones de la misma, y no centrarse en una sola, como viene siendo habitual. Se trata de pensar en el funcionamiento de I@s pobres para que tengan oportunidad de dejar de serlo. En cada Comunidad caben políticas específicas, que no cabe concretar aquí, pero que con seguridad deben comenzar con la mejora del conocimiento de las dimensiones de la pobreza de sus pobres, hombres y mujeres, y que también deben mostrar una especial sensibilidad a la feminización de esa pobreza humana.

\section{BIBLIOGRAFÍA}

ALCAIDE, J. (1993): «La distribución de la renta», en J. L. García Delgado, España, economía, 2. ${ }^{\text {a }}$ ed., Espasa-Calpe, Madrid.

ALLO, F., y HARTCOURT, W. (1997): «From South to the North: Evolving perspectives on Gender and Poverty», Gender and Development, vol. V, n. ${ }^{\circ} 3$.

ATKINSON, A. B. (1987a): «Poverty», en The Palgrave. A dictionary of Economics, vol. 3, MacMillan Press, Londres.

- (1987b): «On the measurement of poverty», Econometrica, 55 (4): 749-764.

AYALA, L. (1998): «Cambio laboral y pobreza», en EDIS-Cáritas, op. cit., Fundación FOESSA y Cáritas Española.

AYALA, L.; MARTíNEZ, R., y RUIZ-HUERTA, J. (1993): «La distribución de la renta en España en los años ochenta: una perspectiva comparada", en VV.AA., I Simposio sobre Igualdad y Distribución de la Renta y la Riqueza, vol. II, Fundación Argentaria, Madrid, pp. 101-136.

AYALA, L., y RENES, V. (1998): «El estudio de la pobreza en España», en EDIS-Cáritas, op. cit., Fundación FOESSA, Madrid.

BAUDRILLARD, J. (1976): La génesis ideológica de las necesidades, Anagrama, Barcelona.

BAZAGA, I.; RAMOS, J. A., y TAMAYO (coords.) (2000): «Pobreza y desigualdad en España: enfoques, fuentes y acción pública», Cuadernos de Gobierno y Administración, n. ${ }^{\circ} 2$, especial monográfico, primer semestre.

BLACKWOOD, D. L., y LYNCH, R. G. (1994): «The Measurement of Inequality and Poverty: a Policy Maker's Guide to the Literature», World Development, vol. 22, n. ${ }^{\circ} 4$.

BOLTVINIK, J. (1992): «El método de medición integrada de la pobreza. Una propuesta para su desarrollo», Comercio Exterior, vol. 42, n. $^{\circ} 4$, abril.

BOSCH, A.; ESCRIBANO, C., y SÁNCHEZ, I. (1989): Evolución de la desigualdad y la pobreza en España: estudio basado en las encuestas de presupuestos familiares 1973-74 y 1980-1981, Instituto Universitario Ortega y Gasset/ Instituto Nacional de Estadística, Madrid.

CANTILLON, S., y NOLAN, B. (1998): «Are married women more deprived than their husbands?», Journal of Social Policy, vol. XXVII, n. ${ }^{\circ} 2$.

CANTÓ, O. (1997): Desempleo y pobreza en la España de los noventa, Documentos de Trabajo de la Fundación FIES, n. ${ }^{\circ} 136$, Madrid. 
CANTÓ, DEL RÍO y GRADÍN (2000): «La situación de los estudios sobre desigualdad y pobreza en España», en Bazaga, Ramos y Tamayo (2000), op. cit.

CASADO PÉREZ, D. (1990): Sobre la pobreza en España, Editorial Hacer, Barcelona.

CONSEJO ECONÓMICO Y SOCIAL (1996): La pobreza y la exclusión social en España, Consejo Económico y Social, Informe 8/1996, Madrid.

COUSINS, P. (1998): «Social Exclusion in Europe: paradigms of social disadvantage in Germany, Spain, Sweden and the U.K.», Policy and Politics, vol. XXVI, n. ${ }^{\circ} 2$.

CHOSSUDOVSKY, M. (1998): «Global poverty in the late 20th Century», Journal of International Affairs, vol. LII, n. ${ }^{\circ} 1$.

DOYAL, L., y GOUGH, I. (1994): Teoría de las necesidades humanas, Icaria Editorial, Barcelona.

DUCLOS, J. Y., y MERCADER-PRATS, M. (1993): «Household composition and classes of equivalence scales: with application to Spain and the UK», Microsimulation Unit Paper, Department of Applied Economics, University of Cambridge.

- (1999): «Household Needs and Poverty: with application to Spain and the UK», Review of Income and Wealth, 45 (1): 77-98.

EDIS (Equipo de Investigación Sociológica)-Caritas (1998): Las condiciones de vida de la población pobre en España, Fundación FOESSA (Fondo de Estudios Sociales y de Sociología Aplicada), Madrid.

- (2000): Las condiciones de vida de la población pobre desde la perspectiva territorial, Fundación FOESSA y Cáritas Española, Madrid.

ESCRIBANO, C. (1990): «Evolución de la pobreza y la desigualdad en España 1973-1987», Información Comercial Española, n. ${ }^{\circ} 686$.

EUROSTAT (1992): Poverty in Figures: Europe in the Early Eighties, Eurostat, Luxembourg.

FERNÁNDEZ MORALES, A. (1992): «La medición de la pobreza a través de los índices. Una síntesis de la literatura», Cuadernos de Ciencias Económicas y Empresariales, n. ${ }^{\circ} 23$.

FLECHA, R. (dir.): Habilidades básicas de la población. Alfabetización funcional en España, Barcelona (mimeo).

GARCÍA LIZANA, A. (1996): La pobreza en España, Ediciones Encuentro, Madrid.

GARCÍA LIZANA, A., et al. (1989): «La riqueza y la pobreza en España bajo una perspectiva regional», Documentación Social, n. ${ }^{\circ} 76$.

GARCÍA NIETO, J. N. (1991): «Nueva pobreza en España», Debats, 35/36.

GEREMEK, B. (1994): Poverty. A history, Blackwell, Oxford.

HAAN, A., y SIMON, M. (1998): «Poverty and Social exclusion in North and South», Institute of Development Studies Bulletin (Sussex), vol. XXIX, n. ${ }^{\circ} 1$.

HAGENAARS, A. J. M. (1985): The perception of Poverty, Proefschrift, Rijsksuniversiteit of Leiden, Netherlands.

- (1987): «A class of poverty indices», International Economic Review, 28, 3, págs. 583-607.

HAGENAARS, A. J. M., y VAN PRAAG, B. M. S. (1985): «A synthesis of poverty line definitions», Review of Income and Wealth, 31: 139-153. 
HARVEY, D., y REED, M. (1996): «The culture of poverty: an ideological analysis», Sociological Perspective, 39, 4 (invierno): 465-495.

HEYZER, N. (1997): “Gender, Economic Growth and Poverty», Development: Journal of the Society for International Development, vol. XL, n. ${ }^{1}$ (publicado por primera vez en 1992, ibidem).

HOWES, S., y OLSON LANJOUW, J. (1998): «Does sample design matter for poverty rate comparison?», Review of Income and Wealth, vol. XLIV, n. ${ }^{\circ} 1$.

IBARRA, P., y UNCETA, K. (coords.) (2001): Ensayos sobre el desarrollo humano, Icaria, Barcelona.

INE (1996): Encuesta de Presupuestos Familiares. Desigualdad y Pobreza en España. Estudio basado en las Encuestas de Presupuestos Familiares 1973-74, 1980-81 y 1990-91, Instituto Nacional de Estadística y Universidad Autónoma de Madrid, Madrid.

JACKSON, C. (1998): «Women and Poverty or Gender and Well-being?», Journal of International Affairs, vol. LII, n. ${ }^{\circ} 1$.

JUÁREZ, M., y RENES, V. (1994): «Estructura social y desigualdad», cap. 2 del V Informe FOESSA, Fundación FOESSA, Madrid.

KABEER, N. (1997): «Tactics and trade-off: revisiting the links between gender and poverty», Institute of Development Studies Bulletin, 28.

LEAL, J., y CORTÉS, L. (1993): «Desigualdades sociales según género y edad», en La Desigualdad social en España, tomo II, Informe de Investigación del Instituto Universitario de Sociología de Nuevas Tecnologías, Universidad Autónoma de Madrid.

LEAL MALDONADO, J. (1992): «La España desigual y el Estado del Bienestar», en España, fin de siglo, Alianza Editorial, Madrid.

LIPTON, M. (1997): «Editorial: Poverty - are there holes in the consensus», en World Development, vol. 25, n. ${ }^{\circ}$, julio, pp. 1003-1007.

MADRUGA, I., y MOTA, R. (1999): Las condiciones de vida de los hogares pobres encabezados por una mujer, Fundación FOESSA y Cáritas Española Ed., Madrid.

MARCOUX, A. (1998): «The feminization of poverty: claims, facts and data needs», Population and Development Review, vol. XXIV, n. ${ }^{\circ}$.

MARTÍN-GUZMÁN, P. (dir.) (1996): Desigualdad y pobreza en España, Universidad Autónoma de Madrid/INE, Madrid.

MARTÍN-GUZMÁN, P., y BELLIDO, N. (1993): «Líneas de pobreza: una estimación de la pobreza subjetiva en España», en La distribución de la renta. I Simposio sobre Igualdad y Distribución de la Renta y la Riqueza, vol. II, Fundación Argentaria, Madrid, pp. 91-100.

MARTÍN-GUZMÁN, BELLIDO y JANO (2001): «La pobreza en España», Papeles de Economía, n. 88 (Distribución de la Renta en España).

MARTÍN REYES, G.; GARCÍA LIZANA, A., y FERNÁNDEZ MORALES, A. (1989): «La distribución territorial de la pobreza en España», en VI Jornadas de Estudio del Comité Español para el Bienestar Social: La pobreza en la España de los ochenta, Editorial Acebo, Madrid.

MARTÍNEZ PEINADO, J. (1999): El capitalismo global, Icaria, Barcelona.

MARTÍNEZ ROMÁN, M. A. (1996): Exclusión y Política Social. Respuestas públicas a las nuevas necesidades sociales en España y el Reino Unido, Tesis Doctoral, Universidad de Alicante. 
MAX-NEEF, M. A. (1982): Desarrollo a escala humana. Conceptos, aplicaciones y algunas reflexiones, Icaria Editorial, Barcelona.

MERCADER-PRATS, M. (1993): «Bajos niveles de renta en España y una comparación con el Reino Unido y Francia», en La distribución de la renta. I Simposio sobre Igualdad y Distribución de la Renta y la Riqueza, vol. II, Fundación Argentaria, Madrid, pp. 137-149.

- (1995): Peut-on mesurer la pauvreté?: Aspects méthodologiques et conceptuels de la mesure de la pauvreté, l'Espagne dans le context Européen, Tesis Doctoral no publicada, Ecole des Hautes Etudes en Sciences Sociales, Delta, París.

- (1998): «Identifying low standards of living: evidence from Spain», Research on Economic Inequality, 8: 155173.

MILANO, S. (1992): La pauvreté dans les pays riches: du constat à l'analyse, Nathan, Paris.

MUÑOZ DE BUSTILLO y ESTEVE MORA, en el Informe General de Cáritas (1998).

NARAYAN, D., et al. (2000): La Voz de los Pobres. ¿Hay alguien que nos escuche?, Banco Mundial.

NUSSBAUM, M. C. (1998): «Capacidades humanas y justicia social», en J. Riechmann (coord.), Necesitar, desear, vivir, Libros de La Catarata, Madrid.

O'HIGGINS, M., y JENKINS, S. (1989): «Poverty in Europe: estimates for the numbers of poverty in 1975, 1980 and 1984», en R. Teekens y B. Van Praag (eds.), Analysing Poverty in the European Community, EUROSTAT, Luxemburgo.

OCDE (1976): Public Expenditure on Income Maintenance Programmes, París.

OLIVER, J. (dir.) (2001): La pobresa a Catalunya. Informe 2001, Fundació «Un Sol Món» de Caixa Catalunya, Barcelona.

OLSON, M. (1996): «Big bills left on the sidewalk: why some nations are rich and others poor?», Journal of Economic Perspectives, vol. X, n. ${ }^{\circ} 2$.

PEARCE, D. (1978): «The feminization of poverty: women, work and Welfare», Urban and Social Change Review, 11.

PÉREZ DE ARMIÑO, K. (2000): Diccionario de Acción Humanitaria y Cooperación al Desarrollo, Icaria Editorial, Barcelona.

PNUD (varios años): Informe sobre Desarrollo Humano, Nueva York.

RENDTEL, U., et al. (1998): «The estimation of poverty dynamics using different measurements of household income», Review of Income and Wealth, vol. XLIV, n. ${ }^{\circ} 1$.

ROWNTREE, B. S. (1901): Poverty: A Study of Townlife, McMillan, London.

RUIZ-CASTILLO, J. (1987): La medición de la pobreza y la desigualdad en España, Banco de España, Estudios Económicos, n. ${ }^{\circ} 42$, Madrid.

RUIZ-HUERTA, J., y MARTíNEZ, R. (1993): «La pobreza en España: ¿qué nos muestran las EPF?», Documentación Social, número monográfico La pobreza en España hoy, n. ${ }^{\circ} 9$.

RUSPINI, E. (1998): «From Rowntree to panel survey: a transition that has transformed the concept of poverty», Sociologia e Ricerca Sociale, 19: 93-123.

SEN, A. (1976): «Poverty: an ordinal approach to measurement», Econometrica, 44, marzo. 
SEN, A. (1981): Poverty and Famines. An essay on Entitlement and Deprivation, Clarendon Press, Oxford.

- (1990): «Gender and Cooperative Conflicts», en I. Tinker (ed.), Persistent inequalities. Women and world development, University Press, Oxford.

- (1995): Nuevo examen de la desigualdad, Alianza Economía, Madrid.

STREETEN, P. (1981): First Things First. Meeting basic human needs in developing countries, Oxford University Press, Washington, EE.UU.

- (1998): «Beyond the six veils: Conceptualizing and measuring poverty», Journal of International Affairs, vol. LII, n. ${ }^{\circ} 1$.

TORTOSA, J. M. (1993): La pobreza capitalista. Sociedad, empobrecimiento e intervención, Tecnos, Madrid.

- (2000): Pobreza y perspectivas de género, Icaria Editorial, Barcelona.

- (2001): El juego global, Icaria Editorial, Barcelona.

TOWNSEND, P. (1993): The International Analysis of Poverty, Harvester Wheatsheaf, Londres.

VAN PRAAG, B.; HAGENAARS, A. J. M., y VAN WEEREN, J. (1982): «Poverty in Europe», Review of Income and Wealth, 28: 345-359.

VEIT-WILSON, J. (1986): «Paradigms of poverty: a rehabilitation of B. S. Rowntree», Journal of Social Policy, 15, 1 (enero): 69-99.

VENANZI, A. (1998): The concept of poverty in sociological research: the case of Latinamerica, ISA.

VV.AA. (1995): Beyond the Threshold. The Measurement and Analysis of Social Exclusion, Room G. Ed. Bristol, Policy Press.

VV.AA. (1980): Human needs. A contribution to the current debate, Lederer, K. Ed., Cambridge, Oelsgeschlager, Gunn \& Hair.

WOOLF, S. (1989): Los pobres en la Europa moderna, Ed. Crítica. Barcelona. 
ABSTRACT

This paper focuses on the study of poverty in Spain, considering the Human Poverty concept, based on a multidimensional poverty approach, as well as using the corresponding methodology applicable to developed countries proposed by the United Nations Development Programme (UNDP). Until now, no systematic research has been done in Spain from this point of view, since most of studies carried out so far have been based on income poverty approach. On the other hand, the territorial differences as much as the gender disparities are very important in the developed societies, and it's basic to know them in order to draw a more precise map and profile of the human poverty in such kind of countries. Therefore this study has been done by regions and by gender, obtaining the corresponding Human Poverty Index and the Gender Human Poverty Index, both general and by regions. By doing so, it's possible to assess how and where poverty affects more women than men.

Key words: Poverty, Human Poverty, Gender, Spanish autonomous regions. 